\title{
Assessment
}

\section{Predictive Properties of the Violence Risk Scale-Sexual Offense Version as a Function of Age}

\begin{tabular}{|r|l|}
\hline Journal: & Assessment \\
\hline Manuscript ID & ASMNT-19-0108.R2 \\
\hline Manuscript Type: & Original Manuscript \\
\hline Keywords: & sexual recidivism, risk assessment, age, change, VRS-SO \\
\hline \multicolumn{2}{|l}{} \\
\end{tabular}

\section{SCHOLARONE ${ }^{m}$ \\ Manuscripts}


Predictive Properties of the Violence Risk Scale-Sexual Offense Version as a Function of Age 


\begin{abstract}
The present study examined the discrimination and calibration properties of Violence Risk ScaleSexual Offense version (VRS-SO) risk and change scores for sexual and violent recidivism as a function of age at release, on a combined sample of 1,287 men who had attended sexual offense specific treatment services. The key aim was to examine to what extent VRS-SO scores can accurately discriminate recidivists from non-recidivists among older cohorts, and if the existing age-related adjustments in the instrument adequately correct for increasing age. VRS-SO risk and change scores showed consistent properties of discrimination for sexual recidivism across the age cohorts, via Area Under the Curve (AUC) and Cox regression survival analysis, as demonstrated through fixed effects meta-analysis. Calibration analyses, employing logistic regression, demonstrated that age at release was consistently incrementally predictive of violent, but not sexual, recidivism after controlling for individual differences on static and dynamic risk factors. E/O index analyses demonstrated that predicted rates of sexual recidivism from VRS-SO scores, particularly when employed with Static-99R, were not significantly different from those observed among age cohorts; however, calibration was weaker for general violence. Implications for use of the VRS-SO in sexual recidivism risk assessment with older offenders are discussed.

Key words: VRS-SO, sexual recidivism, change, risk assessment, age
\end{abstract}

\title{
Methodological Disclosure
}

We report how we determined our sample size, all data exclusions, all manipulations, and all measures in the study 
Predictive Properties of the Violence Risk Scale-Sexual Offense Version as a Function of Age

The assessment of risk for further offending among those convicted of a sexual offense has been a major focus of research over the past three decades, culminating in the development and validation of a number of specially designed instruments. Such instruments, for example Static-99 (Hanson \& Thornton, 1999, 2000), Stable 2007 (Hanson, Harris, Scott, \& Helmus, 2007), and Violence Risk ScaleSexual Offense version (VRS-SO; Wong, Olver, Nicholaichuk, \& Gordon, 2003, 2017), offer structured protocols to rate subjects across an array of factors associated with recidivism, and derive and interpret an overall score or risk categorization linked to an estimate of recidivism. Risk instruments are sometimes revised as knowledge accumulates with further research, and one area that has been a recent focus of risk tool revision (e.g., the development of the revised Static-99R; Helmus, Thornton, Hanson, \& Babchishin, 2012) is the relevance of the age of the individual being assessed, and how to best incorporate age into risk assessments. The impetus for such developments has been the growing literature bases regarding a number of relevant age-related phenomena, including: an inverse link between advancing age and criminal propensity; developmental changes that occur with age that hold relevance for sexual behavior and risk; the empirical impact of aging on sexual recidivism rates; and the weaker performance of some psychometric risk tools observed among older populations, suggesting that age may not have been adequately accounted for. These literatures are briefly reviewed below.

\section{Age and Desistence from Sexual Violence across the Lifespan}

The association between age and general criminal propensity is a well-documented phenomenon, with Lussier and Healey (2009, p. 828) describing it as "one of the most robust and stable empirical findings of criminological research." Specifically, an inverse association has consistently been observed, in which criminal behaviour decreases with advancing age across the lifespan following a peak in adolescence (Farrington, 1986). For instance, a landmark longitudinal study of over 60 years duration (Sampson \& Laub, 2003) concluded that even among those showing early propensity, eventual 
VRS-SO and Age

desistance from crime was the norm: Tracking long-term offending patterns of 480 males identified during childhood as "delinquent," involvement in crime was found to decline across the lifespan (taking into account subject mortality). The average age of desistance, defined as age at last arrest, varied for different offense types; however, beyond the age of 50 rates were consistently very low. Recently, Bekbolatkyzy, Yerenatovna, Maratuly, Makhatovna, and Beaver (2019) analysed longitudinal data from a nationally representative sample of youth to investigate potential causal mechanisms behind the "aging out" effect, finding some support for the impact of both peer group and self-control.

Studies such as the above exploring crime rates across the lifespan have not tended to investigate sexual offending specifically; however, the link between age and recidivism (i.e., sexual reoffending) among those convicted of sexual offenses has been explored. Following an earlier metaanalytic finding by Hanson and Bussière (1998) of an overall small inverse correlation ( $r=-.13$ ) but with notable variability across studies, Hanson (2002) carried out an updated meta-analysis, in which a pooled sample of 4,673 sex offenders from 10 studies was divided into subtypes based on victim type (adults, intrafamilial or extrafamilial children). Hanson's analyses confirmed a linear decline in recidivism rates with increasing age across the whole sample, finding an identical overall correlation magnitude as that reported by Hanson and Bussière $(r=-.13)$. Differential patterns of desistence were apparent between the subgroups, with those who targeted adult victims showing a steady decline in risk from around the age of 40 years, but a later decline for those targeting children, from around 50 years. Individuals who were released past the age of 60 years showed very low rates of recidivism regardless of victim type (3.8\%, relative to the sample base rate of $17.5 \%)$.

Several studies subsequent to Hanson's (2002) meta-analysis have found the same apparently robust inverse relationship between age and sexual recidivism. For instance, Skelton and Vess (2008) explored the link alongside consideration of actuarial risk level among an entire population of all first releases from New Zealand prisons for contact sexual offences across a 15-year period $(N=5,880)$. 
VRS-SO and Age

Skelton and Vess found a decline in sexual reoffending past the age of 50 across risk categories, but also that estimations of risk based on a static scale continued to differentiate sexual reoffending likelihood even amongst the oldest cohorts. More recently, Nicholaichuk, Olver, Gu, and Wong (2014) explored the age-recidivism phenomenon further, drawing data from three years of federal incarceration sexual offending sentence completions from across Canada $(N=2,401)$, with a select focus on the cohort aged 50 years or older at release $(N=542)$ for specific analyses. Among the wider sample, in line with previous research, a steady decrease in sexual recidivism with increasing age at release was observed, with a significant small to moderate inverse relationship found overall (Cramer's $V=-0.16)$. The sexual recidivism base rate was significantly lower among the over-50 cohort (5.6\%) relative to those aged under 50 at release (14.8\%). When the sample was stratified based on a brief actuarial scale devised from six static risk variables available in the dataset, across the majority of risk bands sexual recidivism was lower for the older cohort, with observed rates between a quarter and two-thirds less than the younger cohort. By way of exception, the group of over-50s who scored in the highest risk band exhibited a high rate of sexual recidivism (40.0\%); however, it is important to note this group was small in numbers ( $n=20$, eight of whom were reconvicted). Other studies (e.g., Rettenberger, Briken, Turner, \& Eher, 2015; Thornton, 2006) have reported more complex relationships between age and sexual recidivism as opposed to a simple linear decline, though nonetheless found substantially reduced rates after the age of 60 .

What explanatory mechanisms could be at work to account for the decline in sexual risk with advancing age? In discussing this question, Hanson (2002) highlighted three key possibilities: sex drive/deviant sexual interests, self-control, and offending opportunity. Regarding sex drive, reduced frequency of sexual behavior in general has long been associated with older age in cross-sectional surveys (e.g., Call, Sprecher, \& Schwartz, 1995; Matthias, Lubben, Atchison, \& Schweitzer, 1997), with Call et al. (1995) finding sharp declines commencing from age 50. DeLamater and Moorman (2007) 
VRS-SO and Age

explored whether this effect may be due to factors other than age per se, such as relationship factors (e.g., duration, satisfaction), health problems and associated treatments, and attitudes, finding that although controlling for a range of biological, psychological, and social variables did reduce the strength of the relationship, age remained significantly associated with the frequency of the majority of sexual behaviours across both genders. It is likely that age-related hormonal changes are behind this decline, with androgen (e.g., testosterone) levels known to decline steadily between middle adulthood into older age (e.g., Feldman et al., 2002). As noted by Hanson (2002), to the extent that deviant interests are a key feature of a person's sexual life, which is the case for some but not all who have sexually offended, persistence or otherwise of offending risk would likely reflect changes in the individual's sex drive per se. Further, the availability of opportunities to sexually offend may also contribute to age-related decreases in risk: Hanson (2002) noted that consistent with his meta-analytic findings, recidivism opportunities for those who have offended against adult victims are likely to decline gradually with age due to lifestyle changes, while between their late 20 s through to early 40 s is the age bracket when opportunities to offend against children are likely to be highest (i.e., due to men most commonly having their own children and associating with other young families during this period). Finally, regarding self-control, given that factors such as low self-control and impulsivity are correlates of sexual recidivism (e.g., Hanson \& Bussière, 1998), and that self-control abilities have been shown to be higher amongst older (compared to younger) adults (Isaacowitz, Vaillant, \& Seligman, 2003), it may be that improvements in self-control are a further causal mechanism behind declining sexual re-offending rates with age, as suggested by Hanson (2002).

\section{Age Related Considerations in Sexual Violence Risk Assessment}

Helmus et al. (2012) argued that while it may be desirable to understand the reasons or mechanisms behind the correlation between age and recidivism, such knowledge is not strictly necessary for the purpose of risk assessment; rather, it is the empirical association between a factor and 
VRS-SO and Age

the outcome of interest that is key. Given the robust empirical link between increasing age and declining sexual recidivism, an important question for researchers and practitioners is therefore what impact a subject's age may have on the accuracy of risk assessment tools, and particularly whether estimated rates linked to particular scores remain valid for older individuals. To date, only limited research has been undertaken to explore this issue. Hanson (2006) carried out a study on the performance of the Static-99 (Hanson \& Thornton, 1999, 2000) using a combined sample of $N=3,425$, finding that age at release added significantly to the prediction of sexual recidivism across all risk levels after accounting for Static-99 scores. Predictive accuracy in terms of relative risk was found to be similar across age groups: areas under the receiver operating characteristic curve (AUC) ranged between .66 and .82 with overlapping confidence intervals. With possible values ranging from 0 to 1.0 representing the probability that a randomly selected recidivist would have a higher risk score than a randomly selected nonrecidivist, AUC values of $.556, .643$, and .714 correspond to small, medium, and large effects, respectively (Rice \& Harris, 2005). With respect to absolute risk, however, those in the older age brackets (i.e., from 40 to 50 years and older) showed lower rates of sexual recidivism than what would be expected based on their Static-99 risk category (based on norms published in Harris, Phenix, Hanson, \& Thornton, 2003), meaning that the tool over-estimated absolute risk among these cohorts, across risk levels. This was particularly marked for the 60 and older age bracket. The author concluded that evaluators using this tool should take advanced age into account when estimating risk, a recommendation echoed by Lussier and Healey (2009) based on their later analyses of a Canadian sample of 533 sexual offenders.

More recently, a revised version (Static-99R) was developed, as a means of more robustly improving predictive accuracy amongst older subjects (Helmus et al., 2012). On the basis of updated analyses with an expanded pooled dataset $(N=8,390)$ indicating that age at release was (negatively) incrementally predictive after controlling for the original version total score, and that applying the 
VRS-SO and Age

original age weights resulted in overestimating recidivism among those aged 50 and older, it was determined that revision was necessary. The revised tool, Static-99R, incorporating revised age weights (in which up to three points are subtracted to account for the effect of advancing age on risk), was demonstrated to provide a substantially better fit for those 50 and older than the original tool in terms of absolute recidivism estimates when compared to observed rates (Helmus et al., 2012). In contrast, in a study exploring the links between different measures of age and sexual recidivism risk (Rice \& Harris, 2014), the authors concluded that no adjustments were warranted on the basis of age at release when an actuarial risk tool encompassing an item for age at time of offending was used, such as the Sex Offender Risk Appraisal Guide (SORAG; Quinsey, Harris, Rice, \& Cormier, 2006). The variation in findings across studies underscores the importance of investigating the issue of whether age-related adjustments or revisions may be necessary across different risk tools.

\section{Dynamic Risk Measures and the Effects of Age}

Within the past 15-20 years, the field of sexual recidivism risk assessment has witnessed a proliferation in dynamic risk measures, in recognition of the potential for risk to change and the concordant need for measures that can inform service planning and evaluate changes in risk from treatment or other change agents. Relevant examples include Stable 2007 (Hanson, Harris, Scott, \& Helmus, 2007), the Violence Risk Scale-Sexual Offense version (VRS-SO; Wong, Olver, Nicholaichuk, \& Gordon, 2003, 2017), and the Sex Offender Treatment Information and Progress scale (SOTIPS; McGrath, Lasher, \& Cumming, 2012). Results of meta-analysis support the predictive accuracy of dynamic measures for sexual recidivism at a magnitude that is comparable to static tools, with area under the receiver operating curve (AUC) values (estimated from Cohen's d) of approximately .68 to .69 reported (Hanson \& Morton-Bourgon, 2009; van den Berg et al., 2018). As such, applying the aforementioned Rice and Harris (2005) guidelines, extant static and dynamic measures have broadly moderate accuracy for sexual recidivism, and individual studies further tend to show dynamic measures to be incrementally 
VRS-SO and Age

predictive of sexual recidivism after controlling for static scores (Hanson, Helmus, \& Harris, 2015;

McGrath et al., 2012; Olver et al., 2007). Dynamic tools, however, have not undergone the same level of scrutiny as static measures, such as Static-99R specifically, in terms of how their predictive properties and applications may be impacted by advancing age.

\section{Current Study and Rationale}

Amidst the growing aging correctional population across international jurisdictions (e.g., Boe, Nafekh, Vuong, Sinclair, \& Cousineau, 2003; Dawes, 2009; Handtke, Bretschneider, Wangmo, \& Elger, 2012), including an increasing prosecution of men who have historical sexual offenses, it is becoming increasingly commonplace for evaluators to be assessing men well into their middle age and senior years for sentencing and release decisions. Although the research has demonstrated precipitously declining base rates of recidivism associated with aging, examination of the predictive properties of sexual violence risk tools, particularly dynamic measures, with older offenders has been remarkably scant. This includes: i) to what extent risk scores can adequately differentiate recidivists from nonrecidivists among older offenders (i.e., discrimination); and ii) what recidivism base rates are associated with risk scores on existing tools among older offenders (i.e., calibration); that is, do existing tools adequately account for increasing age?

As such, the present study sought to examine the predictive properties (discrimination and calibration) of risk and change scores from a dynamic tool-the VRS-SO-among different adult age groups from a large multinational treated sexual offender sample used to establish and cross validate the tool (see Olver et al., 2018). The work is necessary to: i) begin filling a gap in the risk assessment field about the role and relevance of increasing age on dynamic risk assessment, and ii) specifically examine the predictive properties of the VRS-SO with different age groups, particularly older offenders in order to inform clinical and psycholegal applications of the VRS-SO with this age group. We examine both 
sexual and violent recidivism given the importance of the assessment and management of risks for both outcomes, and given that age-related changes are associated with a declining frequency of each. The following hypotheses were proposed:

1. Rates of sexual and violent recidivism will show age related declines, with the lowest rates observed in men age $\geq 60$ years.

2. VRS-SO static, dynamic (pre and post), and change scores, and Static-99R scores, will each predict sexual and violent recidivism and show adequate properties of discrimination across different age cohorts.

3. Properties of discrimination will also be demonstrated for VRS-SO factor scores (pre, post, change) across age cohorts.

4. Positive changes (i.e., reductions) in risk, measured by the VRS-SO, will be associated with decreases in sexual and violent recidivism, after controlling for baseline risk (i.e., static and dynamic risk factors), irrespective of age group.

5. Calibration analyses will demonstrate that VRS-SO risk and change scores (or alternatively, Static99R and VRS-SO scores) will remain incrementally associated with sexual and violent recidivism at fixed follow-ups after controlling for age at release. The association between age at release and recidivism is expected to weaken with increasingly stringent controls for risk and change.

6. E/O indices will demonstrate acceptable calibration between expected and observed rates of sexual recidivism generated from logistic regression models based on either the VRS-SO (risk and change scores) or the Static-99R and VRS-SO combined (dynamic risk and change scores), within different age groups. Given that age-related calibration has been weaker for violent recidivism for sexual violence risk tools (Helmus et al., 2012), greater E/O disparities are anticipated.

\section{Method}

\section{Samples and Procedure}


The present study employed four combined samples of incarcerated men convicted for sexual offenses who received sexual offense specific treatment services. The VRS-SO was rated from pretreatment and posttreatment information on each of the samples (three archival and retrospective, one prospective) in their entirety and recidivism data were obtained from updated official criminal record sources. All VRS-SO ratings were completed blind to recidivism outcome and usually by different coders, who were graduate or undergraduate research assistants trained in the measures by one or more members of the VRS-SO development team; the exception was raters for the prospective sample, who were frontline service providers (see sample descriptions below). By necessity, coders for the retrospective samples would have exposure to pretreatment and posttreatment information for the cases, as this is needed to complete change ratings; however, posttreatment information was not reviewed until following the completion of pretreatment ratings, and for the bulk of cases that had electronic files, pretreatment and posttreatment information were stored in separate folders. The combined sample yielded 1,287 cases with complete VRS-SO pretreatment and posttreatment ratings (valid protocols with missing items were prorated following manual instructions), recidivism data, and age at release. The samples and further coding procedures are described as follows.

Clearwater Sex Offender Program I. A sample of 321 consecutive admissions to the Clearwater High Intensity Sex Offender Program (Correctional Service of Canada, CSC) from 1983-1997 (Olver, Wong, Nicholaichuk, \& Gordon, 2007). Historically, the Clearwater Program has been a 6 to 8-month program ( $M=8.0$ months, $S D=2.9)$ that provided services for high-risk need men, although this sample has some heterogeneity in risk and need level as earlier admissions (e.g., 1980s) predated the risk-needresponsivity model (Andrews, Bonta, \& Hoge, 1990) which informed later admissions decisions; however, most admissions still tended to have substantive psychological concerns or treatment needs. VRS-SO ratings were completed retrospectively from detailed institutional files by trained coders and recidivism information (convictions) was obtained from the Canadian Police Information Centre (CPIC). 
VRS-SO and Age

The sample was followed up 17.7 years (SD $=4.3$ ) of which 320 men had 5-year outcome and 314 had 10-year outcome.

Kia Marama Program. A sample of 218 completers of New Zealand's Kia Marama Program for child sex offenders from 1993-2000 at Rolleston Prison (Beggs \& Grace, 2010, 2011). VRS-SO ratings were completed retrospectively by that study's first author (Beggs) and a trained postgraduate research assistant from detailed institutional files and recidivism information (convictions) was obtained from a nationwide database. Although Kia Marama is one of New Zealand's high intensity programs $(M=9.4$ months, $S D=3.7$ ), the sample from the specified time period could be characterized as broadly moderate risk overall and was statistically lower risk on the VRS-SO and Static-99R than Clearwater I (Olver, Beggs Christofferson, Grace, \& Wong, 2014). The sample was followed up 12.3 years (SD =1.8) of which 218 men had 5-year outcome and 187 had 10-year outcome.

National Sex Offender Program. A sample of 570 treated men who had attended CSC's National Sex Offender Program (NaSOP) between 2000-2008 in one of the low $(M=2.2$ months, $S D=1.5, n=$ 165), moderate $(M=5.2$ months, $S D=0.6, n=121)$, or high $(M=9.1$ months, $S D=2.1, n=211)$ intensity streams; information regarding program intensity was not available for $n=73(12.8 \%)$ cases. A given stream was designated for low, moderate, or high risk cases respectively, per Andrews et al's (1990) risk principle (Olver, Nicholaichuk, Kingston, \& Wong, 2014). VRS-SO ratings were available from all five of CSC's regions, with the study having greatest access to ratings from the two institutions within its resident province: one of which (Riverbend Institution) ran a low intensity program and had predominantly low risk men, while the other was a high intensity program (Clearwater) with predominately high risk men. Two cases in the NaSOP sample did not have exact age at release information decreasing this subsample to $n=568$ for age related analyses. VRS-SOs were rated prospectively pretreatment and posttreatment by treatment service providers who were trained on the measure by members of the VRS-SO development team or designates. VRS-SO ratings were extracted 
from electronic files, treatment reports, or hard copies of score sheets. Recidivism data (charges and convictions) were obtained from CPIC. The recidivism data were updated in 2015 to generate a total follow-up of 10.2 years $(S D=2.4$ ) of which 564 men had 5-year outcome, and 307 had 10-year outcome.

Clearwater Sex Offender Program II. A sample of 180 consecutive admissions to the Clearwater High Intensity Sex Offender Program from 1997-2001 ( $M=6.8$ months, $S D=2.4)$, who were subsequently released to the community (Sowden \& Olver, 2017). These were broadly high risk-high need men and the sample did not overlap with the Clearwater participants from the NaSOP sample. VRS-SO ratings were completed retrospectively by that study's first author (Sowden) and trained undergraduate coders on the basis of detailed information from institutional files; recidivism information (convictions) was obtained from CPIC. The sample was followed up 9.1 years $(S D=3.2)$ of which 168 men had 5-year outcome and 105 had 10-year outcome.

\section{Measures}

Static-99R. The Static-99R (Helmus et al., 2012) is a revision of Hanson and Thornton's (1999/2000) original tool with an updated age weighted item. The instrument is a 10-static item empirical actuarial sexual violence risk measure comprised of sexual and nonsexual offense history and offender and victim demographic variables. The measure was originally developed from four international samples in 1999, while the most recent iteration including the revised age weighted item (scored: $1<$ age $35 ; 0$ age $35-39 ;-1$ age $40-59 ;-3$ age $\geq 60$ ) is based on meta-analysis of 24 samples. Possible scores range from -3 to 12. Meta-analytic research from these studies (Helmus et al., 2012) for Static-99R in the prediction of sexual recidivism has demonstrated large in magnitude predictive accuracy $(\mathrm{AUC}=.72, k=24, N=8,390)$.

VRS-SO. The VRS-SO is a sexual violence risk assessment and treatment planning tool comprising 7 static and 17 dynamic items. Each item is rated on a four-point $(0,1,2,3)$ scale, with higher item scores presenting increased risk for sexual violence; all items are weighted equally. The measure was 
VRS-SO and Age

developed from the Clearwater sample referenced previously (Olver et al., 2007) initially in 1999 and successively revised in subsequent years with the addition of new samples and developments in the field. Although the VRS-SO age at release item is not differentially weighted from the other items as with Static-99R, the item is scaled in a manner that assigns a higher risk score to younger ages and lower scores to older ages (scored: $3<$ age $25 ; 2$ age $25-34 ; 1$ age 35 to $44 ; 0$ age $\geq 45$ ). While Static-99R assigns relatively heavy weight in the reverse direction to older age and comparatively less increasing weight to younger ages (score range from 1 to -3 ), the VRS-SO instead assigns a comparatively heavier risk rating to younger ages but a lower risk rating with increasing ages (score range of 3 to 0 ). As such, both age at release items adjust for increasing age with similar ranges; the major difference in scaling on this item between the VRS-SO and Static-99R, is that is that the VRS-SO makes no distinctions after age 45 whereas Static-99R has one more threshold after age 40 (at age 60).

Dynamic items with a 2 or 3 rating are considered criminogenic, treatment targets, and prioritized for treatment, while items with 0 or 1 ratings are low risk items. The items can be summed to generate static, dynamic, and total (static + dynamic) scores ranging from 0-21 (static), 0-51 (dynamic), and 0-72 (total). Factor analyses of the VRS-SO dynamic items have demonstrated that the items can be arranged into three oblique factors termed Sexual Deviance (e.g., sexually deviant lifestyle, sexual compulsivity, deviant sexual preference), Criminality (e.g., interpersonal aggression, substance abuse, impulsivity), and Treatment Responsivity (e.g., cognitive distortions, insight, treatment compliance); the factor domains are employed for case conceptualization and treatment planning (Olver et al., 2007). The VRS-SO dynamic items are designed to assess change from treatment or other change agents across multiple time points through a modified application of the stages of change (SoC) model. Five stages have been operationalized for each of the 17 dynamic items: precontemplation, contemplation, preparation, action, and maintenance. Progression from one stage to next is credited with a 0.5 -point deduction, two stages, 1-point and so on; the one exception is progress from precontemplation to 
VRS-SO and Age

contemplation in which no point deduction is awarded given that there is no behavioral change. SoC ratings are only given to 2 or 3 rated items. A change score is then computed by summing change ratings. On the VRS-SO, ratings at time 1 are often referred to as pretreatment ratings, while ratings at time 2 are similarly referred to as posttreatment.

An Excel workbook, termed the "VRS-SO Calculator" (Mundt, 2015) has been developed for the VRS-SO applying the results of logistic regression to calculate 5 and 10-year rates of sexual and violent recidivism associated with specific VRS-SO risk and change scores (Olver et al., 2018). The calculator can be accessed online for free at https://psynergy.ca/vrs-so. The logistic regression equations were generated from all cases from the four aforementioned Canadian and New Zealand samples $(N=913)$ with a minimum of 10 years follow-up post-release. A prediction model has also been developed for the Static-99R to be used in combination with VRS-SO pretreatment dynamic and change scores, in lieu of the VRS-SO static score.

Recidivism. Sexual recidivism was defined as a new criminal charge or conviction postassessment for a sexually motivated offense, contact or non-contact. Three of the samples employed criminal convictions in the operationalization of sexual recidivism, while the NaSOP sample also included charges. Violent recidivism was defined as any new criminal conviction (all samples) for a personinvolved offense whether it was sexual (e.g., sexual assault, invitation to sexual touching) or nonsexual (e.g., nonsexual assault, homicide, robbery) in nature. For the Canadian samples, outcome data were obtained from a national criminal record database (CPIC) as noted previously, which is a federal service that registers criminal charges and convictions across the country; New Zealand has a similar system. Although shortcomings endemic to the field of recidivism research (re: undetected recidivists) equally apply to official sources of recidivism and these are not error free, data sources such as CPIC are among the most comprehensive and reliable in the world.

\section{Planned Analyses}


VRS-SO and Age

The analyses proceeded in several phases. SPSS 25.0 was used as the default for all analyses unless otherwise indicated. First, we conducted age group comparisons through a one-way MANOVA with Tukey beta post hoc comparisons on Static-99R and VRS-SO scores using the following age at release categories: $<30,30-39,40-49,50-59$, and $\geq 60$. We used this grouping to not only stratify age but also in an effort to maximize the cell size for each group, and hence power. Second, we then compared the five age bands on sexual and violent recidivism outcomes over 5 and 10 -year fixed and unfixed follow-ups through chi square analysis (hypothesis 1).

Third, we conducted an extensive set of discrimination analyses, beginning with computing AUC statistics for VRS-SO and Static-99R among the five age bands for 5-year and 10-year sexual and violent recidivism (hypothesis 2). The lone exception was for the age 60+ group for which we did not fix the follow-up given that there would be so few recidivists as a result ( $n_{\text {recid }}=2$ fixed vs. 5 unfixed) that the AUCs would be unstable. AUC magnitudes were interpreted using the Rice and Harris (2005) guidelines. To examine variation in AUC magnitude across the age groups, we conducted fixed effects meta-analysis of AUCs for Static-99R and VRS-SO risk scores using MedCalc version 19.0.6 (MedCalc Software bvba, Ostend, Belgium, 2019). We report the $Q$ statistic and $I^{2}$ as measures of effect size heterogeneity, and hence, significant variation in AUC magnitude across the age groups. Significant Q values indicate significant heterogeneity in effect size, while $\mathrm{I}^{2}$ values are indexes of percent variability ranging from 0 to 100 , with values of $25 \%, 50 \%$, and $75 \%$ representing small, medium, and large variability, respectively (Higgins, Thompson, Deeks, \& Altman, 2003). A lack of significant variation in the discrimination properties of VRS-SO and Static-99R scores between age groups in terms of AUC magnitudes would be represented by non-significant $\mathrm{Q}$ and/or low $\mathrm{I}^{2}$ values.

Fourth, given the role of the VRS-SO dynamic factor domains in case formulation and service planning, their predictive properties as a function of age are important properties of the tool. Seldom, however, are release and sentencing decisions made on the basis of individual instrument domains, and 
as such, the primary consideration was to examine whether these domains were capable of discriminating recidivists from non-recidivists between the different age groups, and hence their risk relevance. For these analyses, we elected to use Cox regression survival analyses for pretreatment, posttreatment, and change scores on the three dynamic factor domains in the prediction of sexual and violent recidivism among the age bands and simply reported the hazard ratio ( $\mathrm{HR}$, denoted as $\left.e^{B}\right)$ for each analysis (hypothesis 3 ). Cox regression controls for individual differences in follow-up time as a survival analytic technique that includes both a binary frequency dimension (i.e., yes-no recidivism) and a temporal dimension (i.e., time to recidivism), identifying recidivists at their time of recidivism and censoring non-recidivists at the expiration of their follow-up time. The HRs represent the percent change in the hazard of an unwanted outcome (such as recidivism) for every one-unit increase in the predictor variable; values above 1.0 are interpreted to mean that a predictor is associated with increased recidivism, while values below 1.0 mean increasing scores on the predictor are associated with decreased recidivism. For the change score analyses, residualized change scores were used, that is, controlling for pretreatment score, given that the magnitude of the pretreatment score will constrain how much an individual can change in a given domain; regressing the change score on the pretreatment score and obtaining the residual represents the amount of change variance unconstrained by pretreatment score (Beggs \& Grace, 2011). To formally examine variability in HR magnitudes between the age groups, we conducted fixed effects meta-analysis for risk and change scores on each of the factor domains, reporting the overall effect as well as the $Q$ and $I^{2}$ statistics. Meta-analysis of HRs was done using Comprehensive Meta-Analysis 2.0 (Borenstein, Hedges, Higgins, \& Rothstein, 2005).

Fifth, the final set of discrimination analyses entailed examining the incremental validity of risk and change scores to sexual and violent recidivism among the five age groups through Cox regression survival analysis (i.e., to what extent are changes in risk incrementally predictive of changes in recidivism when controlling for baseline or pretreatment risk score). Controls for baseline risk involved either 
VRS-SO and Age

entering the VRS-SO pretreatment total score followed by the change score, or the Static-99R and pretreatment dynamic scores, followed by the change score; for space considerations only the last step of the analyses are reported. The analyses are particularly critical, as they would serve to examine if changes in risk measured by the tool are associated with decreased recidivism, even among older offenders, after controlling for baseline risk and individual differences in follow-up time. Given that some of the analyses would be underpowered due to low base rates and smaller cell sizes for older age groups, variability in HR magnitudes across age groups were formally examined through fixed effects meta analysis (hypothesis 4).

The final set of analyses examined the calibration properties of the VRS-SO as a function of age; specifically, the extent to which the recidivism estimates of the VRS-SO apply across age groups and most notably to older offenders, given their lower rates of recidivism. Logistic regression modelling was employed using a 10-year fixed follow-up for both 5 and 10-year sexual recidivism, the basis for the VRSSO normative sample (Olver et al., 2018). Logistic regression, unlike Cox regression, does not account for individual differences in follow-up time, and thus follow-ups need to be mechanically fixed, such that only cases with sufficient follow-up time (e.g., 5 years, 10 years etc.) are included and cases are counted as recidivists only if they reoffended within the time window. In logistic regression, $B_{0}$ represents the log odds of the recidivism base rate where the predictors equal 0 , while $B_{1}$ values represent the change in the likelihood of a binary event (e.g., recidivism) between adjacent scores on the predictor. The logistic function $\frac{\mathrm{e}^{\mathrm{B} 0+\mathrm{B} 1 \times \mathrm{sccore}}}{\left(1+\mathrm{e}^{\mathrm{B} 0+\mathrm{B} 1 \times \mathrm{Score}}\right)}$ (Tabachnick \& Fidell, 2007) can then be used to generate estimates of recidivism over a defined follow-up for individual scores (or combinations of scores) on a predictor.

Although sexual recidivism is the outcome for which the tool is predominantly used, we also examined violent recidivism given that VRS-SO recidivism estimates are also available and of interest for this outcome. The analyses utilized the normative sample with 10-years follow-up, given that it is this subgroup from which the normative recidivism estimates were derived, and against which age would 
need to demonstrate incremental prediction of outcome controlling for other predictors. For these analyses, we examined the extent to which age at release uniquely predicted 5-year and 10-year sexual recidivism: i) controlling for VRS-SO pretreatment total and change score (i.e., model 5 in the VRS-SO calculator) or, ii) after controlling for Static-99R, VRS-SO pretreatment and change scores (i.e., model 6 of the calculator). If age at release did not uniquely predict sexual recidivism in the normative sample over and above the covariates in these regression models, then a reasonable argument can be advanced that the recidivism estimates generated by the tool apply across age groups (hypothesis 5 ). Age squared was entered in a final block in these analyses to examine if the association between age and recidivism was nonlinear.

Logistic regression was then used to compare observed rates of sexual and violent recidivism over 5 and 10-year follow-ups among the different age groups, to those rates predicted by either the VRS-SO or VRS-SO and Static-99R score combinations referenced previously (hypothesis 6). This was done through the E/O index, in which the number of recidivists expected from VRS-SO score combinations generated via the logistic function, are compared to the actual number of recidivists observed within a given age group (Hanson, 2017). The logistic function can generate recidivism probabilities for all individual cases within a sample, and then these probabilities can be summed across all cases within a reference group (e.g., age cohort) to generate the would be number of recidivists expected for that group on the basis of their VRS-SO and/or VRS-SO Static-99R score combinations alone. E/O values over 1.0 represent the overprediction of recidivism by the expected rates, values under 1.0 represent underprediction of recidivism, and values close to 1.0 represent strong calibration. The $\mathrm{E} / \mathrm{O}$ index is significant when the $95 \%$ confidence intervals do not overlap with 1.0 (Rockhill, Byrne, Rosner, Louie, \& Colditz, 2003): 95\% CI of $\frac{E}{O}$ index $=\left(\frac{E}{o}\right) e^{\left(+/-1.96 \sqrt{\frac{1}{o}}\right)}$

\section{Results}

\section{Age Group Comparisons on Risk and Need}


VRS-SO and Age

Table 1 reports age group comparisons on Static-99R and VRS-SO scale component scores via one-way MANOVA (Pillai's Trace $=.45, F[44,5096]=14.51, p<.001$ ) with Tukey beta post hoc comparisons. On the Static-99R, men $<30$ and 30s scored significantly higher than remaining age groups, while $\geq 60$ men scored significantly lower than all groups. A similar pattern was found for VRSSO static scores, although the $\geq 60$ and 50 s groups did not significantly differ. In terms of dynamic scores, there were no significant age-related differences on dynamic total scores (pre or post) and the only significant group difference on change was $<30$ scoring lower than the 40 s group. For the three dynamic factor domains, there were no significant age-group differences on Treatment Responsivity; however, for Sexual Deviance, the 40s, 50s, and $\geq 60$ groups all scored significantly higher than the $<30$ and 30s groups, while the reverse was observed for the Criminality factor (i.e., the two youngest age groups scored the highest).

\section{Age Group Comparisons on Recidivism}

Table 2 reports base rates of 5-year, 10-year, and overall sexual and violent recidivism for the five age groups. The $<30$ and 30 s groups had significantly higher rates of sexual and violent recidivism than the older three age groups, irrespective of follow-up. The 40 s group had significantly higher rates of general violent recidivism than the $\geq 60$ group across each follow-up, and higher rates of 10-year violence than the 50 s group. There were no significant differences among the three oldest cohorts in base rates of sexual recidivism irrespective of follow-up.

\section{Predictive Accuracy of VRS-SO Scores among Age Groups}

Tables 3 and 4 report the results of ROC analyses and fixed effects meta-analysis for the prediction of sexual and violent recidivism by Static-99R and VRS-SO static, dynamic, and total scores over fixed 5 and 10-year follow-ups. Given the very small number of recidivists for the $\geq 60$ group, we did not fix the follow-up for analyses of this age cohort. Both static measures evinced moderate to high predictive accuracy for 5 and 10-year sexual recidivism across the age groups, although the $<30$ group 
had small in magnitude AUCs for Static-99R. Both sets of measures significantly predicted sexual recidivism at one or more follow-ups in the 50 s and $\geq 60$ cohorts, although the Static-99R did not attain significance with the $\geq 60$. Results of fixed effects meta-analysis demonstrated the pattern in AUC variability across age groups was not significant, although for 10 -year sexual recidivism $I^{2}$ values were closer to moderate. Dynamic scores demonstrated consistency in AUC magnitude across the age groups in the prediction of sexual recidivism as evidenced by non-significant $Q$ and small $I^{2}$ values.

For general violence, Static-99R and the VRS-SO static significantly predicted violent recidivism irrespective of outcomes for all age groups, with the exception of 10-year violence for the 50-59 group. Fixed effects meta analysis demonstrated some variability in AUC magnitudes for the static measures in the prediction of 5-year violence, and significant variability for 10-year violence. VRS-SO dynamic and total scores significantly predicted violence with moderate to high accuracy across the age groups, with fixed effects meta analysis demonstrating no significant variation in prediction magnitude.

Tables 5 and 6 report the results of a series of univariate Cox regressions conducted for the VRSSO dynamic factor score domains across the five age groups in the prediction of sexual and violent recidivism, respectively. Scrutiny of the hazard ratios (HRs) showed some fluctuations in magnitude and most frequently attaining significance for the $<30,30$ s, and 40 s groups. The results of fixed effects meta-analysis, however, demonstrated generally minimal and non-significant variability in HR magnitudes across age groups for all but Treatment Responsivity pretreatment factor scores; posttreatment Treatment Responsivity and Criminality change scores also showed small to moderate but non-significant variation. For general violence, the results of fixed effects meta-analysis demonstrated that each of the three domains, with the exception of pretreatment Sexual Deviance, scores significantly predicted this outcome overall; significant variability in HR magnitudes across age groups was found only for Criminality change scores.

Changes in Risk and Associations with Recidivism as a Function of Age 
VRS-SO and Age

The final set of discrimination analyses examined the association between changes in risk as measured by the VRS-SO dynamic total scores with changes in recidivism between the age groups; the previous section (Tables 5 and 6 ) outlined such associations between changes on the three factors and possible decreased recidivism. Tables 7 and 8 report the results of incremental validity analyses for VRSSO dynamic change total scores controlling for baseline risk, in the prediction of sexual and violent recidivism, respectively. Regression models controlling for VRS-SO pretreatment total scores (models 15) are presented in the top half, Static-99R and VRS-SO pretreatment dynamic models (6-10) are in the bottom half. For models 1-5, VRS-SO pretreatment scores and change score HRs were in the expected direction for each age cohort, and significantly associated with their targeted outcome overall. Results of fixed effects meta-analysis demonstrated little variability in HR magnitude for the change scores across the age groups, but moderate variability for VRS-SO pretreatment scores. This pattern was repeated for Static-99R and VRS-SO pretreatment dynamic score associations with sexual recidivism, both of which showed moderate variability $\left(I^{2}\right)$ in HR magnitude across the age groups, while change score HRs were stable and did not have significant variability.

Similar trends were observed for the prediction of violent recidivism (Table 8). Fixed effects meta-analysis demonstrated that change score HR magnitudes showed minimal and non-significant variability across age groups in the prediction of decreased general violence after controlling for baseline risk, whether this employed the VRS-SO (models 1-5) or the combined Static-99R-VRS-SO models (models 6-10). VRS-SO pretreatment total scores showed also stability in the prediction of general violence across the age groups. Greater variation was observed for the risk predictor variables for models 6-10. Specifically, Static-99R HR magnitudes showed significant and large in magnitude variability in the prediction of general violence across age groups, particularly for the $<30$ group, while VRS-SO dynamic pretreatment HRs had small in magnitude variation. Taken together, the results demonstrate that VRS-SO and Static-99R scores showed some age-related variation in effect size 
VRS-SO and Age

magnitude, but only after controlling for change, while change score HRs were stable in their unique associations with outcome, controlling for pretreatment risk.

\section{Calibration of VRS-SO Risk and Change Scores as a Function of Age}

Logistic regression. The final set of analyses examined the calibration properties of VRS-SO and Static-99 scores as a function of age. This began with formal examination of incremental prediction of age at release for 5 and 10-year sexual and violent recidivism (minimum 10-year follow-up for both outcomes) controlling for Static-99R and VRS-SO risk and change scores in the VRS-SO normative sample $(N=913)$. The results of logistic regression are reported in Tables 9 (sexual recidivism) and 10 (violent recidivism). The first block, which is essentially the VRS-SO calculator model referenced previously (minus two cases which did not have exact age information) demonstrated VRS-SO pretreatment total (i.e., static + dynamic) scores and change scores to be uniquely associated with sexual recidivism across both follow-ups. When age was added in the second block all three covariates independently predicted sexual recidivism; the addition of age squared to examine a possible nonlinear association did not consistently add to prediction. For the Static-99R and VRS-SO (pretreatment dynamic and change) models, the three variables incrementally predicted sexual recidivism in the expected directions but age at release was not significantly incrementally predictive when entered in the second block, nor was the squared age term when entered in the third block.

Two variations on these models were run to examine the effect of adding static and dynamic scores as a single covariate (e.g., VRS-SO pretreatment total) or when they are examined as separate covariates (e.g., Static-99R and pretreatment dynamic scores), on the association of age with recidivism. These analyses were secondary and are reported in the supplemental materials. When the VRS-SO static and pretreatment dynamic items were entered as separate covariates, followed by change and age at release, age at release was no longer independently significantly predictive of 5 or 10 -year sexual recidivism. By contrast, when Static-99R and pretreatment dynamic scores were summed to create a 
VRS-SO and Age

single quantity and entered as a single covariate followed by change and age at release, age at release became uniquely predictive of outcome. This finding and its implications are elaborated further in the Discussion, but in short, it was apparent that the risk mitigating effects of the age variable within each of the static tools is diluted when it becomes absorbed into a larger aggregate measure through being combined with the VRS-SO dynamic score. This suggests that the VRS-SO age at release item (S1) at a bare minimum adequately corrects for increasing age, but the effect is attenuated when the static score is combined with dynamic score to generate a much larger quantity with the VRS-SO total score.

The results examining the incremental association between age at release and violent recidivism controlling for sexual violence risk and change are reported in Table 10. In these analyses, all risk, change, and age at release covariates (Blocks 1 and 2) were uniquely predictive of 5 and 10-year violent recidivism. This was irrespective of whether the Static-99R was substituted for the VRS-SO static, or whether baseline risk was examined as a single vs. multiple covariates. In contrast to the sexual recidivism analyses in which the age at release squared term was not significant (suggesting a linear association with sexual recidivism), for violent recidivism, it was significant for the majority of analyses suggesting a possible nonlinear association between age at release and violence.

E/O Indices. Table 11 (sexual recidivism) and 12 (violent recidivism) report calibration results from calculation of $\mathrm{E} / \mathrm{O}$ indices and $95 \% \mathrm{Cls}$ that compare the expected number of recidivists for a given age group as predicted from their VRS-SO scores (with or without Static-99R), to the actual number of recidivists observed within that age group. The E/O indices employ the same predictor models akin to those illustrated in Block 1 of Tables 9 and 10, although for the purposes of the exercise all available cases were examined (per Helmus et al., 2012) and exact $B_{1}$ and $B_{0}$ values used are presented in the table notes. As seen in Table 11, none of the E/O index values were significant for the Static-99R-VRS-SO model in the prediction of 5 and 10-year sexual recidivism, meaning that the rates of sexual recidivism predicted by test scores for each of the age groups did not depart substantially from those observed 
within each group from the sample. There was some underprediction for 30 s men and more substantial overprediction for $\geq 60$ group, which reduced with the longer follow-up. For the VRS-SO scores only, the measure significantly underpredicted sexual recidivism for the 30 s group but no other $E / O$ index values were significant. Although the index was not significant for the oldest cohort, there were still three times as many recidivists predicted for this group than what was observed, even though the predicted rate of recidivism was still considerably lower than the other age cohorts.

Table 12 paints a different picture in terms of calibration for general violent recidivism. Broadly, any disparities seen in the prediction of sexual recidivism for the age groups was magnified for the prediction of violence. For the Static-99R-VRS-SO model, some underprediction was evident for the younger cohorts and overprediction for the older cohorts, with the E/O index attaining significance for the 50s group at both follow-ups. For the VRS-SO model, underprediction was significant for the younger age groups and overprediction was significant for the older age groups, being most pronounced for the $\geq$ 60 group. This is not surprising given that the VRS-SO was not developed to assess risk for general violence, and the weaker age-related calibration for general violence relative to that for sexual recidivism is consistent with the pattern of age-related calibration findings for Static-99R (Helmus et al., 2012).

\section{Discussion}

The current study examined the discrimination and calibration properties of VRS-SO risk and change scores as a function of age. This was done both to fill an existing gap in dynamic risk instrument research examining the role and relevance of age, and specifically how this may inform clinical and psycholegal applications of the VRS-SO, particularly with older offenders.

\section{Discrimination Properties of VRS-SO Scores as a Function of Age}

Discrimination analyses (AUC and Cox regression) demonstrated that VRS-SO risk and change scores could differentiate sexual and violent recidivists with acceptable accuracy across age groups, 
VRS-SO and Age

even the oldest cohort, consistent with previous discrimination findings with actuarial sexual recidivism risk tools (Hanson, 2006). The results of fixed effects meta-analysis demonstrated that the variability in AUC magnitudes for sexual or violent recidivism across the age groups was generally not significant, particularly for the dynamic scores. The results of discrimination analysis also supported the change properties of VRS-SO scores across age groups, with changes in risk showing inverse associations with decreased sexual and violent recidivism controlling for baseline risk. As with the AUC findings, despite mild fluctuations in hazard ratio magnitudes for residual change scores across the age cohorts, the results of fixed effects meta-analysis demonstrated that the variability in effect size magnitude was not significant and generally small in magnitude, particularly for the aggregate change score.

\section{Age-Related Calibration Properties of VRS-SO Scores}

The older age groups in the current study showed the lowest rates of sexual and violent recidivism than the younger cohorts as expected. The results of logistic regression and E/O index analyses were used to examine to what extent VRS-SO scores capture increasing age, how this translates into recidivism estimates, and to what extent predicted rates of recidivism from VRS-SO scores (with or without Static-99R) align with those observed within each of the age groups. The results of logistic regression demonstrated that both models uniquely predicted sexual and violent recidivism after accounting for age at release. In turn, age at release was no longer significantly associated with sexual recidivism in the integrated VRS-SO-Static-99R model although it remained significant for the VRS-SO only model. Age at release was consistently significantly associated with violent recidivism irrespective of regression model.

Age-related calibration was directly examined though E/O indices, which reinforced these findings. Calibration was strongest for sexual recidivism in that $E / O$ indices were not significant within each of the age groups for either model for 18 of the 20 analyses; there was slight underprediction of sexual recidivism for younger age groups and more noticeable (but not significant) overprediction for 
the $\geq 60$ s group. Importantly, both models predicted successively lower rates of sexual recidivism as a function of increasing age. Any age-related disparities in calibration, however, were magnified for general violence in the same direction from the sexual recidivism, with approximately half of $E / O$ indices attaining significance and overprediction being greatest in the $\geq 60$ s group. Taken together, the results demonstrate stronger age-related calibration of the VRS-SO for sexual recidivism, particularly when used with Static-99R, compared to its weaker calibration for general violence especially with older offenders. This is not surprising given that the VRS-SO (and Static-99R) were developed to assess risk for sexual recidivism, while other risk-relevant considerations not captured by these tools account for individual variation in propensity to violence, including age.

A caveat to the $\mathrm{E} / \mathrm{O}$ index is that it can amplify the magnitude of differences when the observed number of recidivists is very small, making calibration look worse than it may actually be; this might be most pronounced for older groups. A means to address this would be to supplement the E/O index with a variation on it such as E-O index (David Thornton, personal communication, September 18, 2019). For instance, in the $\geq 60$ group, with two observed sexual recidivists over a fixed 10-year follow-up (2/76 $=2.6 \%$ ) and an expected number of 5 recidivists (divided by $76=6.6 \%$ ) based on the VRS-SO only, this generated an E/O index of 2.5 amounting to overprediction by two and a half times as many recidivists. By contrast this would generate an $E-O$ index value of $(5-2)=3$ recidivists or $(6.6 \%-2.6 \%)$ or $4 \%$. This is much different than if the number of observed sexual recidivists was 50; a corresponding $\mathrm{E} / \mathrm{O}$ index of 2.5 would translate into an $\mathrm{E}-\mathrm{O}$ index of $(125-50)=75$, or overprediction by 75 additional recidivists, a substantial disparity. Using the present study data, the magnitude of disparities, at least for sexual recidivism, are more consistent between the age cohorts (ranging from about $1 \%$ to $5 \%$ ). As such, further examination of the $\mathrm{E}-\mathrm{O}$ index and extension to further samples in future research is warranted as a variant on this important index of calibration.

\section{Accounting for Increased Age in Sexual Violence Risk Assessment}


VRS-SO and Age

The VRS-SO can be used clinically either on its own or in combination with Static-99R substituted in place for the VRS-SO static items, via the online "calculator" noted previously, in which 5 and 10-year estimates for sexual or violent recidivism, associated with specific risk and change scores, can be obtained through use of the logistic function. While the recidivism estimates are not stratified or adjusted based on advancing age, applications of the VRS-SO account for age by: 1) the age items on the respective tools (i.e., Static-99R or VRS-SO static), and 2) changes captured on the dynamic items that may be attributable to the forces of aging.

There was some evidence that age influences calibration for sexual recidivism and that some regression models may more fully account for the effects of increasing age on risk reduction than others. Supplemental analyses further indicated that the age correction in prediction models may be influenced by the manner in which the covariates are entered. For instance, when VRS-SO static and dynamic items were examined as separate covariates, age at release no longer incrementally predicted sexual recidivism; however, when VRS-SO pretreatment dynamic and Static-99R scores were combined into a single quantity, age at release was incrementally predictive. This may be that the age correction of shorter static instruments becomes diluted when added onto part of a longer scale; however, such conclusions need to be tempered in light of the post hoc nature of these analyses, and cannot be assumed to be stable, absent replication.

In this work, we examined the potential for reweighting the age at release item on the VRS-SO through adding additional negative weights for advancing ages; however, we found that this did not alter the trend of age continuing to be predictive when the static and dynamic total were entered as a single quantity, nor did it substantially improve age correction even when static and dynamic scores were entered as separate covariates. A potential revision of the VRS-SO's age at release item will remain a future consideration for the instrument's development group pending further research and compelling data. A further possibility may involve adding age at release as a separate covariate to the logistic 
VRS-SO and Age

function of the VRS-SO calculator to provide more comprehensive adjustment for age; however, this is tempered by data demonstrating age at release not to be consistently incrementally predictive of sexual recidivism across all regression models.

Finally, we argue that it is important to acknowledge the potential impact of aging on dynamic risk factors and how this may be expressed in observed changes on these domains. Changes on the VRSSO dynamic items can occur in response to different risk mitigating agents, of which correctional/forensic treatment is only one. It is anticipated that age-related changes will occur across many risk relevant domains (e.g., decreased sex drive, decreased victim access, improved emotional and behavioral controls; see Hanson, 2002), and that these may be captured in dynamic item risk and change ratings. That age may influence dynamic risk in such a manner further underscores the importance of using dynamic instruments that can reflect such changes in sexual violence risk assessments with older offenders.

\section{Limitations and Conclusions}

There are noteworthy limitations to the present research with implications for further work. The most significant limitation in our view was the relatively limited subsample of men who were released after age 60 . While the existing subsample of older men enabled testing several key hypotheses about the discrimination and calibration properties of VRS-SO scores, the low recidivism base rates coupled with the smaller $n$ precluded more extensive analyses employing fixed follow-ups and may also have implications for the stability of some findings with this age group (e.g., with there being only two observed sexual recidivists for the $\geq 60$ s group in E/O analyses). Use of the VRS-SO normative sample to examine age-related discrimination and calibration also increases the potential for model overfitting, and the present study findings and conclusions would be strengthened through replication and extension to other samples. A further consideration is that, time free in the community post release has important implications for continued risk reduction and cessation of offending; that is, the longer an 
VRS-SO and Age

individual stays out of custody and remains crime free, the less likely is that individual to return to custody for a new sexual or violent crime (Hanson, Harris, Letourneau, Helmus, \& Thornton, 2018). It was beyond the scope of the present study to examine the interaction of risk, time free, and/or support services in the community or even prerelease to estimated rates of future sexual offending, when the focus instead was on the psychometric properties of a sexual violence risk tool among age stratified groups. This is a worthy line of future research with implications for use of the VRS-SO with older offenders and how recidivism projections factor in time free in the community.

These limitations notwithstanding, the substantive findings broadly support the VRS-SO's discrimination and calibration properties for sexual recidivism with different age groups, including for older individuals; age-related calibration for the oldest cohort was strongest when the VRS-SO dynamic risk and change scores were used in tandem with Static-99R. Calibration findings, however, indicated fairly substantial overprediction of general violence among older offenders by the VRS-SO only model, and as such, users would be advised to use the integrated VRS-SO-Static-99R model if appraising risk for general violence with older offenders (and in such instances such a purpose may be better served by a general violence risk tool). The optimal way to incorporate age into the VRS-SO and its applications has yet to be determined. Further research will inform various possibilities (e.g., reweighting the age item, revising or adding predictors in online calculator), and whether they sufficiently strengthen the age correction with older offenders to merit additional revisions to the tool. 


\section{References}

Andrews, D. A., Bonta, J., \& Hoge, R. D. (1990). Classification for rehabilitation: Rediscovering psychology. Criminal Justice and Behavior, 17, 19-52. doi: 10.1177/0093854890017001004

Barbaree, H. E., Blanchard, R., \& Langton, C. M. (2003). The development of sexual aggression through the life span: The effect of age on sexual arousal and recidivism among sex offenders. Annals of the New York Academy of Sciences, 989, 59-71.

Beggs, S. M., \& Grace, R. C. (2010). Assessment of dynamic risk factors: An independent validation study of the Violence Risk Scale: Sexual Offender Version. Sexual Abuse: A Journal of Research and Treatment, 22, 234-251. doi:10.1177/1079063210369014

Beggs, S. M., \& Grace, R. C. (2011). Treatment gains for sexual offenders against children predicts reduced recidivism: A comparative validity study. Journal of Consulting and Clinical Psychology, 79, 182-192. doi: $10.1037 / a 0022900$

Bekbolatkyzy, D. S., Yerenatovna, D. R., Maratuly, Y. A., Makhatovna, A. G., \& Beaver, K. M. (2019). Aging out of adolescent delinquency: Results from a longitudinal sample of youth and young adults. Journal of Criminal Justice, 60, 108-116.

Boe, R., Nafekh, M., Vuong, B., Sinclair, R., \& Cousineau, C. (2003). The changing profile of the federal inmate population: 1997 and 2002. Ottawa, Canada: Research Branch, Correctional Service of Canada.

Borenstein, M., Hedges, L., Higgins, J., \& Rothstein, H. (2005). Comprehensive meta-analysis (Version 2). Englewood, NJ: Biostat

Call, V., Sprecher, S., \& Schwartz, P. (1995). The incidence and frequency of marital sex in a national sample. Journal of Marriage and the Family, 57, 639-652. doi: 10.2307/353919

Dawes, J. (2009). Ageing prisoners: Issues for social work. Australian Social Work, 62, 258-271. doi: $10.1080 / 03124070902803475$ 
VRS-SO and Age

DeLamater, J., \& Moorman, S. M. (2007). Sexual behavior in later life. Journal of Aging and Health, 19, 921-945. doi: 10.1177/0898264307308342

Farrington, D. P. (1986). Age and crime. Crime and justice, 7, 189-250. doi:10.1086/449114

Feldman, H. A., Longcope, C., Derby, C. A., Johannes, C. B., Araujo, A. B., Coviello, A. D., ... \& McKinlay, J. B. (2002). Age trends in the level of serum testosterone and other hormones in middle-aged men: longitudinal results from the Massachusetts male aging study. The Journal of Clinical Endocrinology \& Metabolism, 87, 589-598. doi: 10.1210/jcem.87.2.8201

Handtke, V., Bretschneider, W., Wangmo, T., \& Elger, B. S. (2012). Facing the challenges of an increasingly ageing prison population in Switzerland: In search of ethically acceptable solutions. Bioethica Forum, 5, 134-141. doi:

Hanson, R. K. (2002). Recidivism and age: Data from 4,673 sexual offenders. Journal of Interpersonal Violence, 17, 1046-1062. doi: 10.1177/088626002236659

Hanson, R. K. (2006). Does Static-99 predict recidivism among older sexual offenders? Sexual Abuse: $A$ Journal of Research and Treatment, 18, 343-355. doi: 10.1177/107906320601800403

Hanson, R. K. (2017). Assessing the calibration of actuarial risk scales: A primer on the E/O index. Criminal Justice and Behavior, 44, 26-39. doi:10.1177/0093854816683956

Hanson, R. K., \& Bussiere, M. T. (1998). Predicting relapse: a meta-analysis of sexual offender recidivism studies. Journal of Consulting and Clinical Psychology, 66, 348. doi: 10.1037/0022-006X.66.2.348

Hanson, R. K., Harris, A. J. R., Letourneau, E., Helmus, L. M., \& Thornton, D. (2018). Reductions in risk based on time offense free in the community: Once a sex offender, not always a sex offender. Psychology, Public Policy, and Law, 24, 48-63. doi:10.1037/law0000135

Hanson, R. K., Harris, A. J., Scott, T. L., \& Helmus, L. (2007). Assessing the risk of sexual offenders on community supervision: The Dynamic Supervision Project (Vol. 5, No. 6). Ottawa, Ontario: Public Safety Canada. 
VRS-SO and Age

Hanson, R. K., \& Morton-Bourgon, K. E. (2009). The accuracy of recidivism risk assessments for sexual offenders: A meta-analysis of 118 prediction studies. Psychological Assessment, 21, 1-21. doi:10.1037/a0014421

Hanson, R. K., \& Thornton, D. (1999). Static 99: Improving actuarial risk assessments for sex offenders. (User Report 99-02). Ottawa: Department of the Solicitor General of Canada.

Hanson, R. K., \& Thornton, D. (2000). Improving risk assessments for sex offenders: A comparison of three actuarial scales. Law and Human behavior, 24, 119-136. doi: 10.1023/A:1005482921333

Harris, A., Phenix, A., Thornton, D., \& Hanson, R. K. (2003). Static 99: Coding rules revised 2003. Ottawa, Ontario: Solicitor General Canada.

Helmus, L., Thornton, D., Hanson, R. K., \& Babchishin, K. M. (2012). Improving the predictive accuracy of Static-99 and Static-2002 with older sex offenders: Revised age weights. Sexual Abuse: A Journal of Research and Treatment, 24, 64-101. doi: 10.1177/1079063211409951

Isaacowitz, D. M., Vaillant, G. E., \& Seligman, M. E. (2003). Strengths and satisfaction across the adult lifespan. The International Journal of Aging and Human Development, 57, 181-201. doi:

10.2190/61EJ-LDYR-Q55N-UT6E

Lussier, P., \& Healey, J. (2009). Rediscovering Quetelet, again: The “aging" offender and the prediction of reoffending in a sample of adult sex offenders. Justice Quarterly, 26, 827-856. doi: $10.1080 / 07418820802593360$

Matthias, R. E., Lubben, J. E., Atchison, K. A., \& Schweitzer, S. O. (1997). Sexual activity and satisfaction among very old adults: results from a community-dwelling Medicare population survey. The Gerontologist, 37, 6-14.

McGrath, R. J., Lasher, M. P., Cumming, G. F. (2012) Sex Offender Treatment Intervention and Progress Scale (SOTIPS): Psychometric properties and incremental predictive validity with Static-99R. Sexual Abuse: A Journal of Research and Treatment, 24, 431-458. doi: 10.1177/1079063211432475 
VRS-SO and Age

MedCalc Statistical Software version 19.0.6 (MedCalc Software bvba, Ostend, Belgium; https://www.medcalc.org; 2019)

Mundt, J. C. (2015). VRS-SO calculator. Retrieved at: www.psynergy.ca

Nicholaichuk, T. P., Olver, M. E., Gu, D., \& Wong, S. C. P. (2014). Age, actuarial risk, and long-term recidivism in a national sample of sex offenders. Sexual Abuse: A Journal of Research and Treatment, 26, 406-428. doi: 10.1177/1079063213492340

Olver, M. E., Mundt, J. C., Thornton, D., Beggs Christofferson, S. M., Kingston, D. A., Sowden, J. N., ... \& Wong, S. C. P. (2018). Using the Violence Risk Scale-Sexual Offense Version in sexual violence risk assessments: Updated risk categories and recidivism estimates from a multisite sample of treated sexual offenders. Psychological Assessment, 30, 941-955. doi: 10.1037/pas0000538.

Olver, M. E., Nicholaichuk, T. P., Kingston, D. A., \& Wong S. C. P. (2014). A multisite examination of sexual violence risk and therapeutic change. Journal of Consulting and Clinical Psychology, 82, 312324. doi: $10.1037 / \mathrm{a} 0035340$

Olver, M. E., Wong, S. C. P., Nicholaichuk, T., \& Gordon, A. (2007). The validity and reliability of the Violence Risk Scale-Sexual Offender version: Assessing sex offender risk and evaluating therapeutic change. Psychological Assessment, 19, 318-329. doi: 10.1037/1040-3590.19.3.318

Prochaska, J. O., DiClemente, C. C., \& Norcross, J. C. (1992). In search of how people change: Applications to the addictive behaviors. American Psychologist, 47, 1102-1114. doi: 10.1037/0003066X.47.9.1102

Quinsey, V. L., Harris, G. T., Rice, M. E., \& Cormier, C. A. (2006). Violent Offenders: Appraising and Managing Risk. American Psychological Association.

Rettenberger, M., Briken, P., Turner, D., \& Eher, R. (2015). Sexual offender recidivism among a population-based prison sample. International Journal of Offender Therapy and Comparative Criminology, 59, 424-444. doi: 10.1177/0306624X13516732 
Rice, M. E., \& Harris, G. T. (2005). Comparing effect sizes in follow-up studies: ROC area, Cohen's d, and r. Law and Human Behavior, 29, 615-620. doi: 10.1007/s10979-005-6832-7

Rice, M. E., \& Harris, G. T. (2014). What does it mean when age is related to recidivism among sex offenders? Law and Human Behavior, 38, 151-161. doi: 10.1037/lhb0000052

Rockhill, B., Byrne, C., Rosner, B., Louie, M. M., \& Colditz, G. (2003). Breast cancer risk prediction with a log-incidence model: Evaluation of accuracy. Journal of Clinical Epidemiology, 56, 856-861. doi:10.1016/S0895-4356(03)00124-0

Sampson, R. J., \& Laub, J. H. (2003). Life-course desisters? Trajectories of crime among delinquent boys followed to age 70. Criminology, 41, 555-592. doi: 10.1111/j.1745-9125.2003.tb00997

Skelton, A., \& Vess, J. (2008). Risk of sexual recidivism as a function of age and actuarial risk. Journal of Sexual Aggression, 14, 199-209. doi: 10.1080/13552600802267098

Sowden, J. N., \& Olver, M. E. (2017). Use of the Violence Risk Scale Sexual Offender Version and the Stable 2007 to assess sexual offender treatment change. Psychological Assessment, 29, 293-303. doi: $10.1037 /$ pas0000345

Tabachnick, B. G., \& Fidell, L. S. (2007). Using multivariate statistics fifth edition. Boston, MA: Allyn and Bacon.

Thornton, D. (2006). Age and sexual recidivism: A variable connection. Sexual Abuse: A Journal of Research and Treatment, 18, 123-135. doi: 10.1177/107906320601800202

van den Berg, J. W., Smid, W., Schepers, K., Wever, E., van Beek, D., Janssen, E., \& Gijs, L. (2018). The predictive properties of dynamic sex offender risk assessment instruments: A meta-analysis. Psychological Assessment, 30, 179-191. doi: 10.1037/pas0000454

Wong, S., Olver, M. E., Nicholaichuk, T. P., \& Gordon, A. (2003, 2017). The Violence Risk Scale: Sexual Offense version (VRS-SO). Regional Psychiatric Centre and University of Saskatchewan, Saskatoon, Saskatchewan, Canada. 
Table 1

Static-99R and VRS-SO Score Age Group Comparisons

\begin{tabular}{|c|c|c|c|c|c|c|}
\hline Risk measure & $\begin{array}{c}<30 \\
(n=312)\end{array}$ & $\begin{array}{c}30 \mathrm{~s} \\
(n=384)\end{array}$ & $\begin{array}{c}40 \mathrm{~s} \\
(n=356)\end{array}$ & $\begin{array}{c}50 \mathrm{~s} \\
(n=158)\end{array}$ & $\begin{array}{c}\geq 60 \\
(n=77)\end{array}$ & \\
\hline & $M(S D)$ & $M(S D)$ & $M(S D)$ & $M(S D)$ & $M(S D)$ & F-test \\
\hline Static-99R & $5.1(2.1)$ & $4.6(2.3)$ & $2.5(2.4)^{a, b}$ & $2.3(2.6)^{a, b}$ & $-0.3(2.5)^{a, b, c, c, d}$ & $130.03 * * *$ \\
\hline \multicolumn{7}{|l|}{ VRS-SO } \\
\hline Static & $10.8(3.7)$ & $9.5(4.2)^{\mathrm{a}}$ & $7.8(4.7)^{\mathrm{a}, \mathrm{b}}$ & $7.3(4.5)^{a, b}$ & $6.2(4.6)^{a, b, c}$ & $35.65^{* * *}$ \\
\hline Dynamic pre & $26.0(8.0)$ & $25.6(7.8)$ & $24.9(8.1)$ & $25.4(8.3)$ & $24.2(7.8)$ & 1.31 \\
\hline Dynamic post & $22.8(8.2)$ & $21.8(7.8)$ & $20.8(7.7)$ & $21.7(8.7)$ & $20.3(7.5)$ & $3.25^{*}$ \\
\hline Change & $3.2(2.4)^{c}$ & $3.8(2.4)$ & $4.1(2.7)$ & $3.7(2.8)$ & $3.9(3.2)$ & $5.51 * * *$ \\
\hline Total pre & $36.8(10.5)$ & $35.1(10.7)$ & $32.7(11.4)^{\mathrm{a}}$ & $32.8(11.5)^{\mathrm{a}}$ & $30.3(11.1)^{a, b}$ & $9.74^{* * *}$ \\
\hline Total post & $33.6(10.7)$ & $31.3(10.7)$ & $28.6(10.9)^{a}$ & $29.0(11.7)^{a}$ & $26.4(10.8)^{a, b}$ & $12.99 * * *$ \\
\hline Sexual deviance pre & $6.4(4.1)^{c, d, e}$ & $7.0(3.9)^{c, d, e}$ & $8.0(4.1)^{\mathrm{e}}$ & $8.7(3.9)$ & $9.5(3.6)$ & $16.86^{* * *}$ \\
\hline Sexual deviance post & $5.6(3.7)^{\mathrm{c}, \mathrm{d}, \mathrm{e}}$ & $5.9(3.4)^{d, e}$ & $6.7(3.5)^{e}$ & $7.3(3.6)$ & $7.9(3.4)$ & $11.95^{* * *}$ \\
\hline Criminality pre & $9.6(3.6)$ & $9.1(4.0)$ & $7.7(4.1)^{\mathrm{a}, \mathrm{b}}$ & $7.3(4.1)^{a, b}$ & $5.2(3.5)^{a, b, b, c, d}$ & $29.61^{* * *}$ \\
\hline Criminality post & $8.7(3.5)$ & $7.9(3.6)$ & $6.6(3.5)^{a, b}$ & $6.5(3.9)^{a, b}$ & $4.7(3.5)^{\mathrm{a}, \mathrm{b}, \mathrm{b}, \mathrm{d} d}$ & $29.86^{* * *}$ \\
\hline Treatment responsivity pre & $6.5(2.5)$ & $6.2(2.4)$ & $6.2(2.6)$ & $6.3(2.6)$ & $6.5(2.6)$ & 0.81 \\
\hline Treatment responsivity post & $5.5(2.6)$ & $5.1(2.5)$ & $5.0(2.5)$ & $5.3(2.7)$ & $5.4(2.5)$ & 1.82 \\
\hline
\end{tabular}

Note: Results of one-way omnibus MANOVA: Pillai's Trace $=.45, F(44,5096)=14.51, p<.001$. F-test results for main effect of age on a given measure: $* * * p<.001, * p<.05$. Results of Tukey beta post hoc multiple comparisons: ${ }^{a}=$ lower than $<30$ group, ${ }^{b}=$ lower than 30 s group, ${ }^{c}=$ lower than 40 sroup, ${ }^{d}=$ lower than 50 s group, ${ }^{\mathrm{e}}=$ lower than $\geq 60$ group. 
Running head: VRS-SO and Age

Table 2

Age Group Base Rates of Sexual and Violent Recidivism

\begin{tabular}{|c|c|c|c|c|c|}
\hline \multirow{2}{*}{$\begin{array}{l}\text { Recidivism } \\
\text { criterion }\end{array}$} & $<30$ & $30-39$ & $40-49$ & 50-59 & $60+$ \\
\hline & $\%(n)$ & $\%(n)$ & $\%(n)$ & $\%(n)$ & $\%(n)$ \\
\hline \multicolumn{6}{|l|}{ Sexual } \\
\hline 5-year & $14.8(46 / 311)$ & $15.3(58 / 378)$ & $6.3(22 / 348)^{a, b}$ & $8.4(13 / 155)^{a, b}$ & $2.6(2 / 76)^{a, b}$ \\
\hline 10-year & $22.4(57 / 255)$ & $23.5(68 / 289)$ & $12.5(29 / 232)^{a, b}$ & $10.2(9 / 88)^{a, b}$ & $4.3(2 / 47)^{a, b}$ \\
\hline Overall & $24.0(75 / 312)$ & $20.8(80 / 384)$ & $10.7(38 / 356)^{a, b}$ & $12.7(20 / 158)^{a, b}$ & $6.5(5 / 77)^{a, b}$ \\
\hline \multicolumn{6}{|l|}{ Violent } \\
\hline 5-year & $33.4(104 / 311)$ & $29.9(113 / 378)$ & $13.5(47 / 348)^{a, b}$ & $11.0(17 / 155)^{a, b}$ & $4.0(3 / 76)^{a, b}$ \\
\hline 10-year & $49.4(126 / 255)$ & $43.9(127 / 289)$ & $26.3(61 / 232)^{a, b}$ & $12.5(11 / 88)^{a, b, c}$ & $4.3(2 / 47)^{a, b}$ \\
\hline Overall & $52.6(164 / 312)$ & $41.7(160 / 384)$ & $23.9(85 / 356)^{a, b}$ & $17.1(27 / 158)^{a, b}$ & $7.8(6 / 77)^{a, b}$ \\
\hline
\end{tabular}

Note: chi square analysis between age groups: ${ }^{\mathrm{a}}=$ lower than $<30$ group, ${ }^{\mathrm{b}}=$ lower than $30-39$ group, ${ }^{\mathrm{c}}=$ lower than 40-49 group, $^{\mathrm{d}}=$ lower than 50-59 group, $^{\mathrm{e}}=$ lower than $60+$ group 


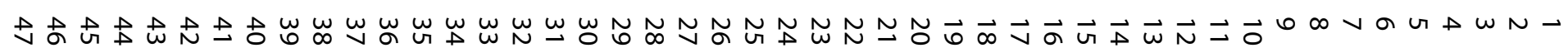

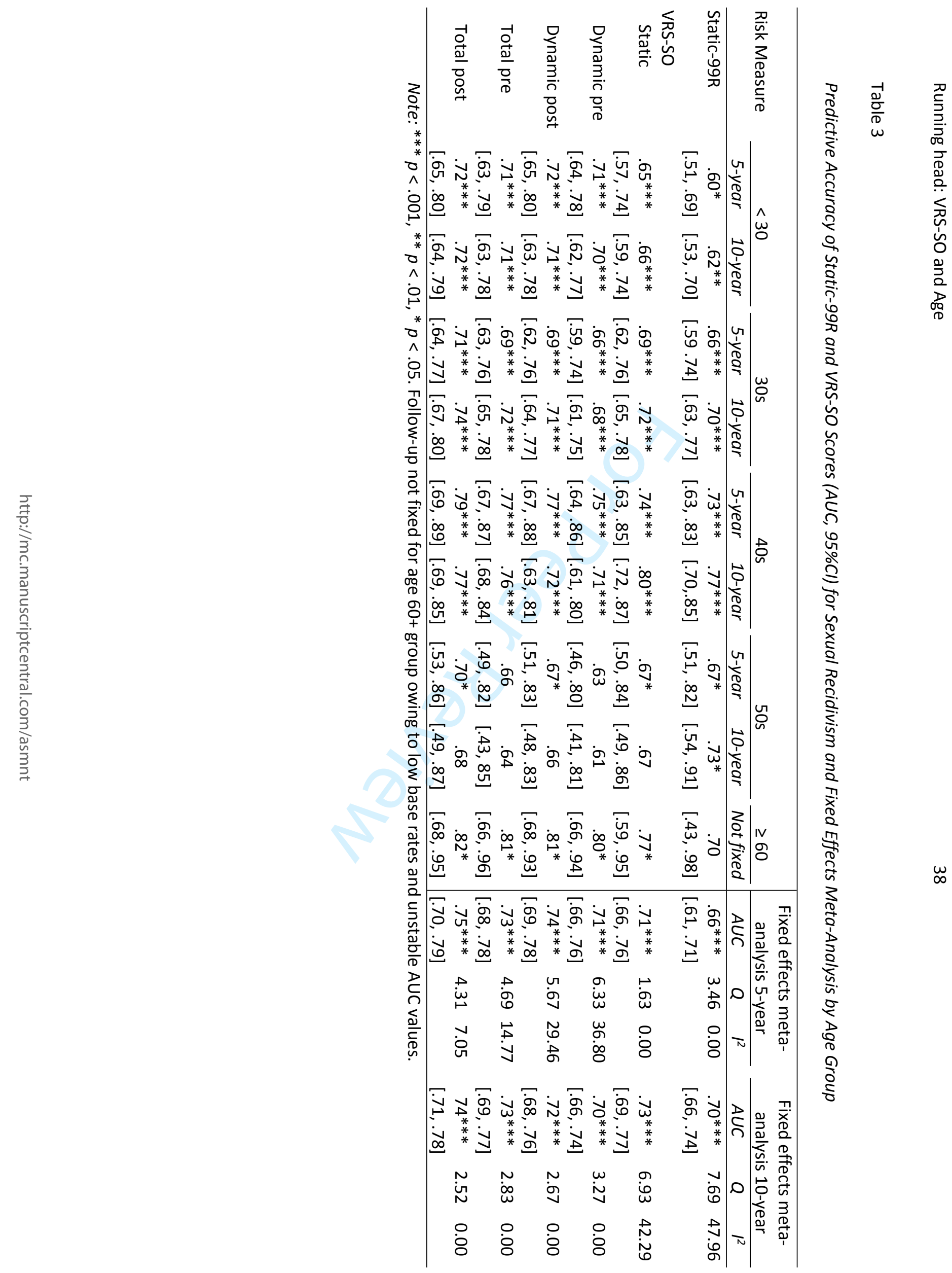




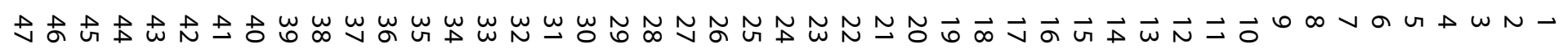

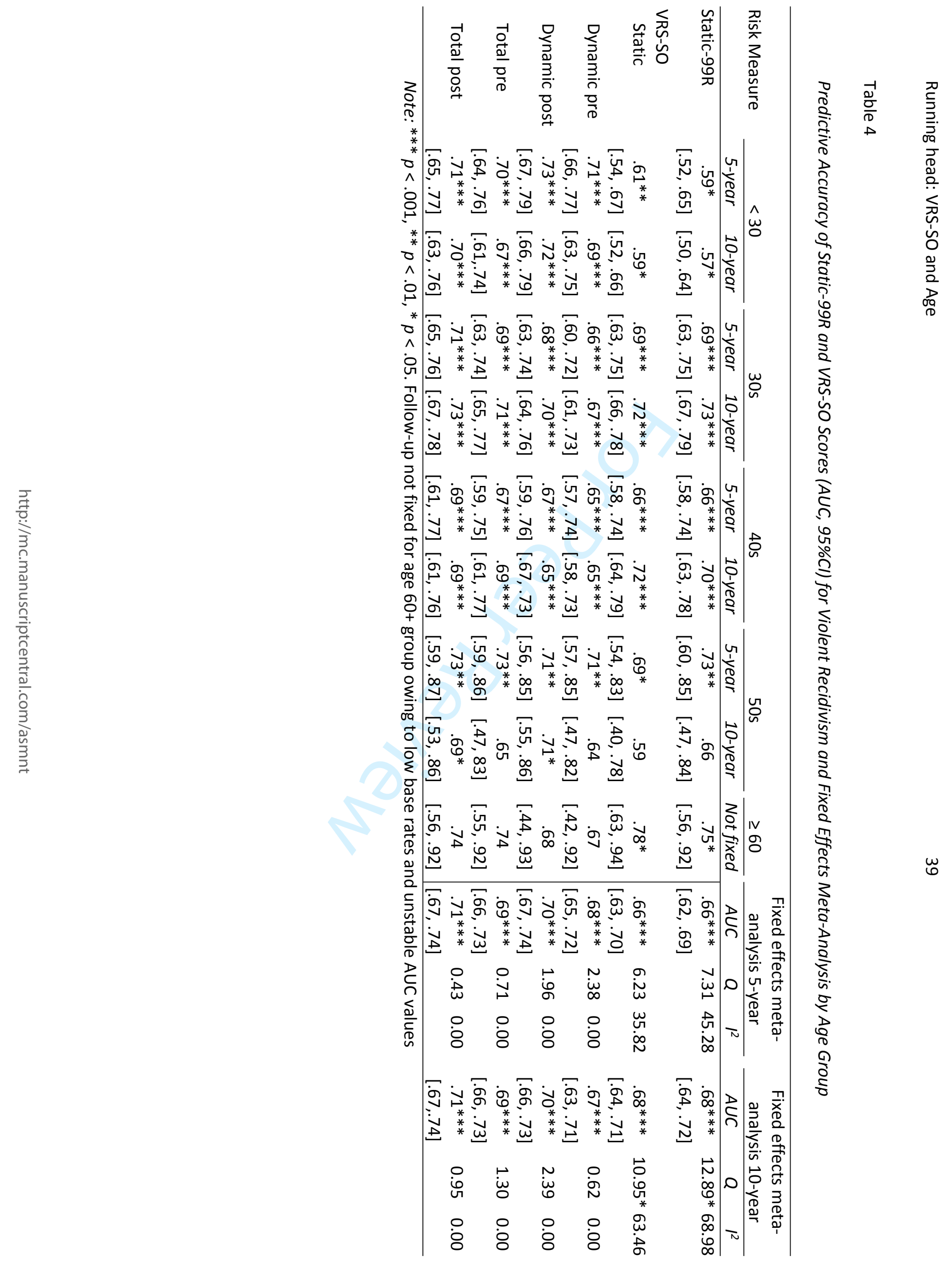




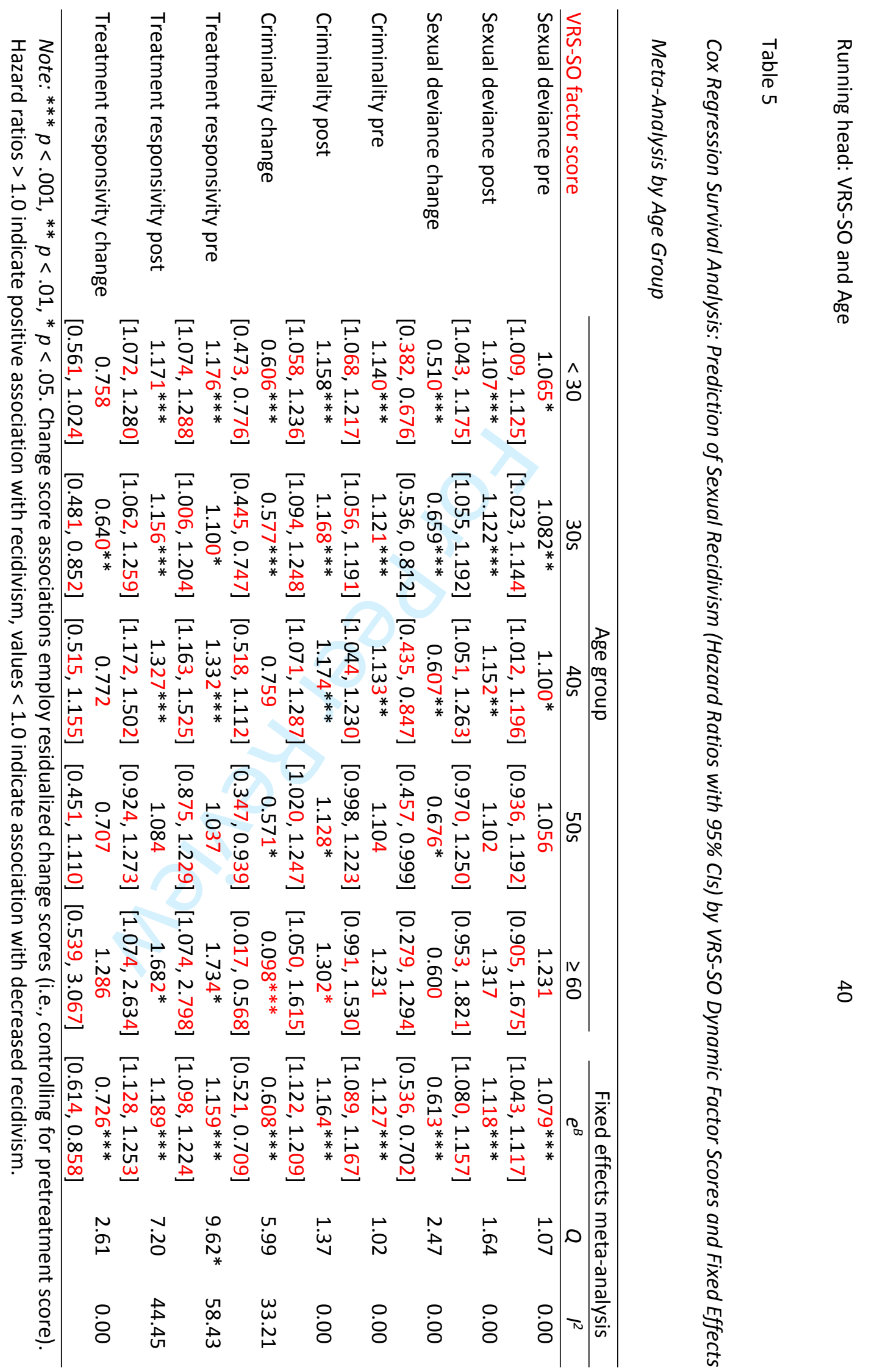




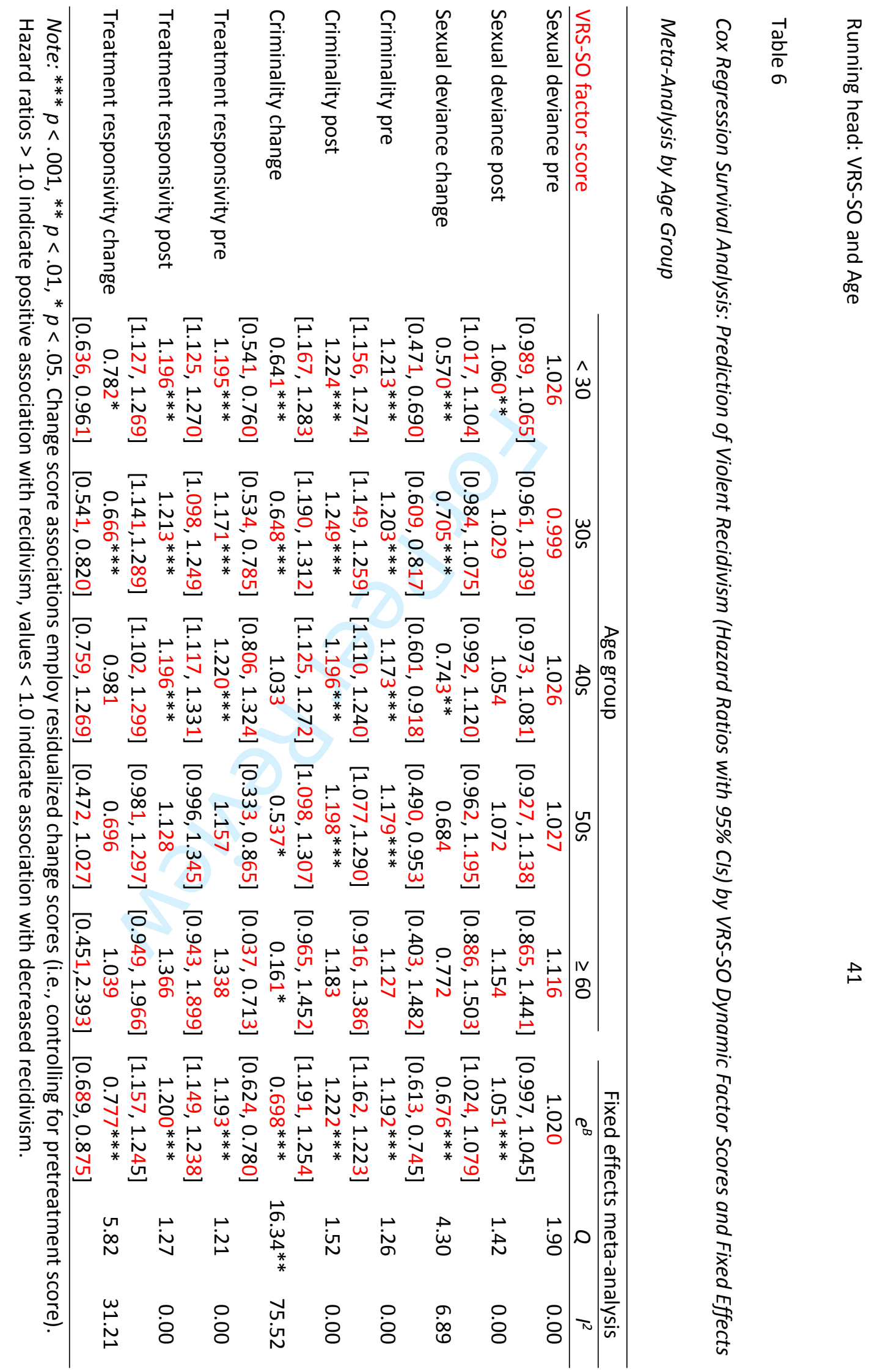

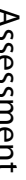


Table 7

Cox Regression Survival Analysis: Incremental Prediction of Static and Dynamic Risk and Change Scores for Sexual Recidivism as a Function of Age with Fixed Effects Meta-Analysis of Hazard Ratios

\begin{tabular}{|c|c|c|c|c|c|c|c|}
\hline \multirow{2}{*}{ Age grou } & \multirow{2}{*}{$\begin{array}{c}\text { Regression } \\
\text { Model (1-10) }\end{array}$} & \multicolumn{6}{|c|}{ Sexual recidivism } \\
\hline & & $B$ & $S E$ & Wald & $p$ & $e^{B}$ & $L L, U L$ \\
\hline & VRS-SO models & & & & & & \\
\hline \multirow{2}{*}{$<30$} & 1 VRS-SO total pre & .055 & .011 & 25.67 & $<.001$ & 1.057 & $1.034,1.080$ \\
\hline & VRS-SO change & -.120 & .048 & 6.25 & .012 & 0.887 & $0.807,0.974$ \\
\hline \multirow[t]{2}{*}{$30 \mathrm{~s}$} & 2 VRS-SO total pre & .059 & .011 & 30.06 & $<.001$ & 1.061 & $1.038,1.083$ \\
\hline & VRS-SO change & -.150 & .045 & 10.96 & .001 & 0.861 & $0.788,0.941$ \\
\hline \multirow[t]{2}{*}{$40 \mathrm{~s}$} & 3 VRS-SO total pre & .089 & .017 & 27.22 & $<.001$ & 1.093 & $1.057,1.129$ \\
\hline & VRS-SO change & -.144 & .059 & 6.01 & .014 & 0.866 & $0.772,0.972$ \\
\hline \multirow[t]{2}{*}{$50 s$} & 4 VRS-SO total pre & .033 & .019 & 3.22 & .073 & 1.034 & $0.997,1.073$ \\
\hline & VRS-SO change & -.143 & .083 & 3.00 & .083 & 0.867 & $0.737,1.019$ \\
\hline \multirow[t]{2}{*}{$\geq 60$} & 5 VRS-SO total pre & .121 & .048 & 6.29 & .012 & 1.129 & $1.027,1.241$ \\
\hline & VRS-SO change & -.164 & .135 & 1.48 & .224 & 0.849 & $0.652,1.105$ \\
\hline
\end{tabular}

Fixed effects meta-analysis: $\quad$ VRS-SO total pre: $e^{B}=1.062[1.049,1.075], p<.001 ; Q=9.44, p=.051 ; l^{2}=57.63$ VRS-SO change: $e^{B}=0.872[0.828,0.918], p<.001 ; Q=0.33, p=.988 ; l^{2}=0.00$

\begin{tabular}{|c|c|c|c|c|c|c|c|}
\hline \multicolumn{8}{|c|}{ Static-99R and VRS-SO models } \\
\hline \multirow[t]{3}{*}{$<30$} & 6 Static-99R & -.016 & .062 & 0.07 & .793 & 0.984 & $0.871,1.111$ \\
\hline & VRS-SO dynamic pre & .070 & .015 & 20.89 & $<.001$ & 1.072 & $1.041,1.105$ \\
\hline & VRS-SO change & -.124 & .048 & 6.55 & .010 & 0.884 & $0.804,0.971$ \\
\hline \multirow[t]{3}{*}{$30 \mathrm{~s}$} & 7 Static-99R & .180 & .061 & 8.64 & .003 & 1.197 & $1.062,1.349$ \\
\hline & VRS-SO dynamic pre & .040 & .016 & 6.09 & .014 & 1.041 & $1.008,1.075$ \\
\hline & VRS-SO change & -.135 & .045 & 9.02 & .003 & 0.873 & $0.800,0.954$ \\
\hline \multirow[t]{3}{*}{$40 \mathrm{~s}$} & 8 Static-99R & .230 & .083 & 7.60 & .006 & 1.259 & $1.069,1.482$ \\
\hline & VRS-SO dynamic pre & .066 & .024 & 7.62 & .006 & 1.068 & $1.019,1.120$ \\
\hline & VRS-SO change & -.148 & .060 & 6.05 & .014 & 0.862 & $0.766,0.970$ \\
\hline \multirow[t]{3}{*}{$50 \mathrm{~s}$} & 9 Static-99R & .215 & .107 & 4.00 & .045 & 1.240 & $1.004,1.530$ \\
\hline & VRS-SO dynamic pre & -.007 & .033 & 0.05 & .826 & 0.993 & $0.931,1.059$ \\
\hline & VRS-SO change & -.142 & .081 & 3.08 & .079 & 0.868 & $0.740,1.017$ \\
\hline \multirow[t]{3}{*}{$\geq 60$} & 10 Static-99R & -.052 & .214 & 0.06 & .806 & 0.949 & $0.624,1.443$ \\
\hline & VRS-SO dynamic pre & .200 & .093 & 4.66 & .031 & 1.222 & $1.019,1.465$ \\
\hline & VRS-SO change & -.214 & .132 & 2.61 & .106 & 0.808 & $0.623,1.047$ \\
\hline
\end{tabular}

Fixed effects meta-analysis: $\quad$ Static-99R: $e^{B}=1.129[1.052,1.211], p=.001 ; Q=9.33, p=.053 ; R^{2}=57.13$ VRS-SO dynamic pre: $e^{B}=1.054[1.035,1.073], p<.001 ; Q=8.32, p=.081 ; I^{2}=51.90$ VRS-SO change: $e^{B}=0.868[0.825,0.915], p<.001 ; Q=0.37, p=.985 ; l^{2}=0.00$ Note: Significant $\mathrm{p}$-values in bold font. VRS-SO total is the sum of static and dynamic items. 
VRS-SO and Age

Table 8

Cox Regression Survival Analysis: Incremental Prediction of Static and Dynamic Risk and Change Scores for Violent Recidivism as a Function of Age with Fixed Effects Meta-Analysis of Hazard Ratios

\begin{tabular}{|c|c|c|c|c|c|c|c|}
\hline \multirow{2}{*}{ Age group } & \multirow{2}{*}{$\begin{array}{l}\text { Regression } \\
\text { Model (1-10) }\end{array}$} & \multicolumn{6}{|c|}{ Violent recidivism } \\
\hline & & $B$ & SE & Wald & $p$ & $e^{B}$ & $L L, U L$ \\
\hline \multirow{3}{*}{$<30$} & VRS-SO models & & & & & & \\
\hline & 1 VRS-SO total pre & .051 & .008 & 42.99 & $<.001$ & 1.052 & $1.036,1.068$ \\
\hline & VRS-SO change & -.111 & .032 & 11.93 & .001 & 0.895 & $0.840,0.953$ \\
\hline \multirow[t]{2}{*}{$30 \mathrm{~s}$} & 2 VRS-SO total pre & .056 & .008 & 55.85 & $<.001$ & 1.058 & $1.043,1.074$ \\
\hline & VRS-SO change & -.141 & .032 & 18.98 & $<.001$ & 0.868 & $0.815,0.925$ \\
\hline \multirow[t]{2}{*}{$40 s$} & 3 VRS-SO total pre & .066 & .011 & 38.13 & $<.001$ & 1.068 & $1.046,1.091$ \\
\hline & VRS-SO change & -.070 & .039 & 3.20 & .074 & 0.933 & $0.864,1.007$ \\
\hline \multirow[t]{2}{*}{$50 \mathrm{~s}$} & 4 VRS-SO total pre & .047 & .017 & 8.12 & .004 & 1.048 & $1.015,1.083$ \\
\hline & VRS-SO change & -.125 & .070 & 3.18 & .075 & 0.882 & $0.769,1.012$ \\
\hline \multirow[t]{2}{*}{$\geq 60$} & 5 VRS-SO total pre & .087 & .039 & 4.84 & .028 & 1.091 & $1.009,1.178$ \\
\hline & VRS-SO change & -.131 & .124 & 1.13 & .288 & 0.877 & $0.688,1.117$ \\
\hline
\end{tabular}

Fixed effects meta-analysis: $\quad$ VRS-SO total pre: $e^{B}=1.059[1.0491 .070], p<.001 ; Q=2.82, p=.588 ; I^{2}=0.00$ VRS-SO change: $e^{B}=0.896[0.864,0.929], p<.001 ; Q=1.64, p=.802 ; l^{2}=0.00$

\begin{tabular}{|c|c|c|c|c|c|c|c|}
\hline \multicolumn{8}{|c|}{ Static-99R and VRS-SO models } \\
\hline \multirow[t]{3}{*}{$<30$} & 6 Static-99R & .001 & .041 & 0.00 & .979 & 0.999 & $0.921,1.083$ \\
\hline & VRS-SO dynamic pre & .069 & .011 & 39.34 & $<.001$ & 1.071 & $1.048,1.094$ \\
\hline & VRS-SO change & -.115 & .032 & 12.71 & $<.001$ & 0.891 & $0.836,0.949$ \\
\hline \multirow[t]{3}{*}{$30 \mathrm{~s}$} & 7 Static-99R & .217 & .044 & 24.79 & $<.001$ & 1.243 & $1.141,1.354$ \\
\hline & VRS-SO dynamic pre & .035 & .011 & 9.36 & .002 & 1.035 & $1.012,1.058$ \\
\hline & VRS-SO change & -.123 & .032 & 14.73 & $<.001$ & 0.885 & $0.831,0.942$ \\
\hline \multirow[t]{3}{*}{$40 \mathrm{~s}$} & 8 Static-99R & .208 & .055 & 14.29 & $<.001$ & 1.232 & $1.105,1.372$ \\
\hline & VRS-SO dynamic pre & .047 & .016 & 8.36 & .004 & 1.048 & $1.015,1.082$ \\
\hline & VRS-SO change & -.073 & .040 & 3.42 & .064 & 0.929 & $0.860,1.004$ \\
\hline \multirow[t]{3}{*}{ 50s } & 9 Static-99R & .213 & .091 & 5.53 & .019 & 1.238 & $1.036,1.478$ \\
\hline & VRS-SO dynamic pre & .022 & .028 & 0.64 & .424 & 1.023 & $0.968,1.080$ \\
\hline & VRS-SO change & -.136 & .069 & 3.87 & .049 & 0.873 & $0.763,0.999$ \\
\hline \multirow[t]{3}{*}{$\geq 60$} & 10 Static-99R & .290 & .188 & 2.39 & .122 & 1.337 & $0.925,1.932$ \\
\hline & VRS-SO dynamic pre & .030 & .076 & 0.16 & .692 & 1.031 & $0.888,1.196$ \\
\hline & VRS-SO change & -.125 & .134 & 0.87 & .351 & 0.883 & $0.679,1.147$ \\
\hline
\end{tabular}

Fixed effects meta-analysis: $\quad$ Static-99R: $e^{B}=1.146[1.092,1.203], p<.001 ; Q=17.65, p=.001 ; l^{2}=77.34$ VRS-SO dynamic pre: $e^{B}=1.055[1.042,1.069], p<.001 ; Q=5.16, p=.272 ; l^{2}=22.41$ VRS-SO change: $e^{B}=0.898[0.865,0.933], p<.001 ; Q=1.19, p=.879 ; l^{2}=0.00$ Note: Significant $\mathrm{p}$-values in bold font. VRS-SO total is the sum of static and dynamic items. 


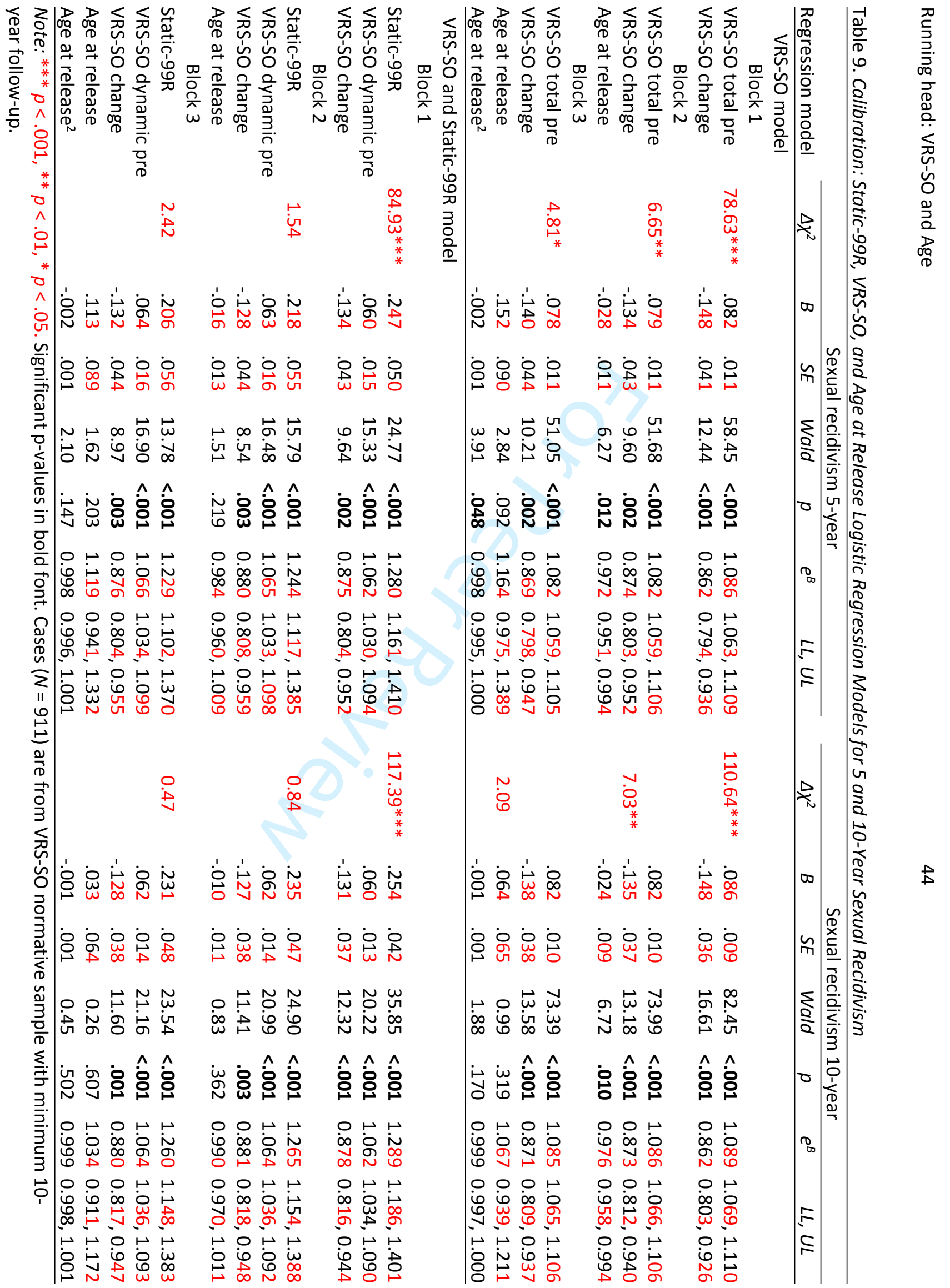




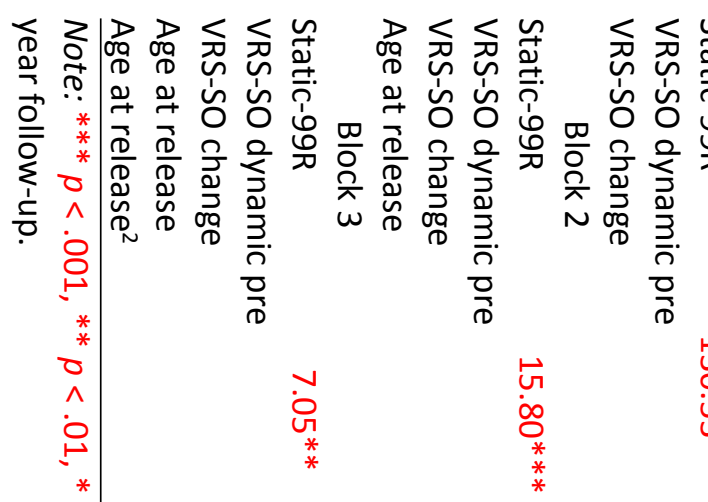

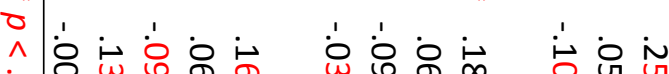

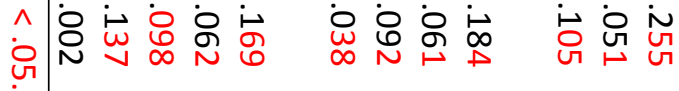

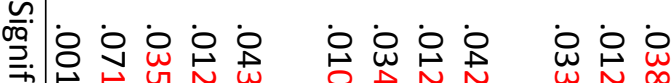

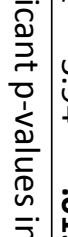

음

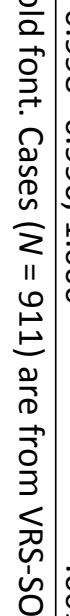

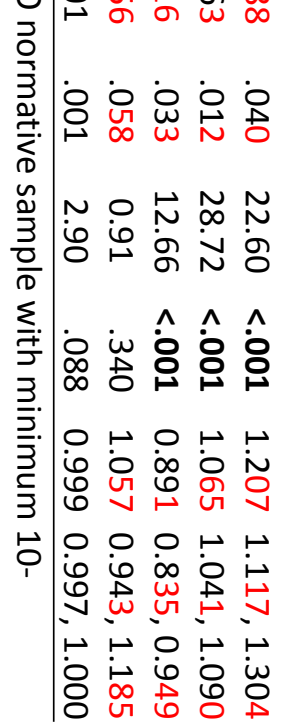

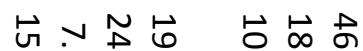

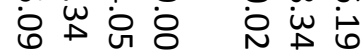
审审宫官 ○ 造总客总 웁 io ज 잉 니 0

ㅇํ

审密

우

串 w

$\circ \mapsto \mapsto$

ต ํำ

웅

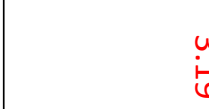

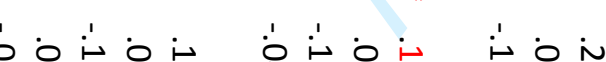

吕占完它 完悹总总

ஸ 秥

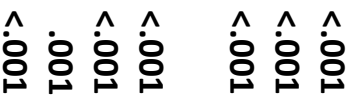

○ํ

v

우

$\circ \circ \mapsto \mapsto$

i

○。

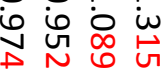

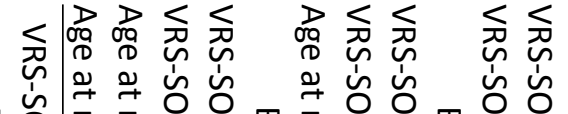

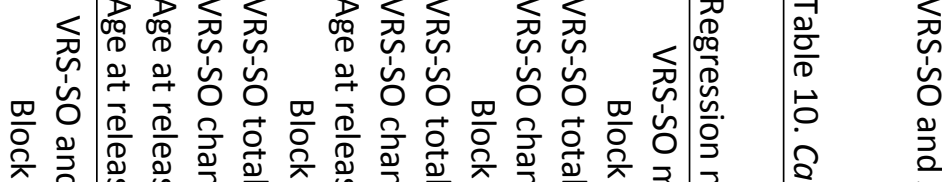

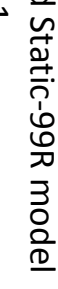

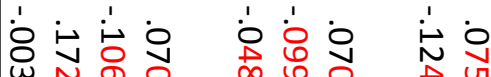

官完岀宫

$\infty$ u

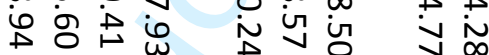

它

우우

ivi

우우입 우

i

ज. 0 ज

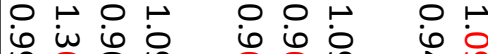

๒ூ 
Table 11

Calibration: E/O Index Analyses Comparing Observed Rates of 5 and 10-Year Sexual Recidivism Among Age Cohorts to Logistic Regression Estimates Generated by VRS-SO Risk and Change Score Combinations (with and without Static-99R).

\begin{tabular}{|c|c|c|c|c|c|c|c|c|}
\hline \multirow[b]{2}{*}{ Age } & \multicolumn{2}{|c|}{ Observed } & \multicolumn{3}{|c|}{ Static-99R and VRS-SO predicted } & \multicolumn{3}{|c|}{ VRS-SO predicted } \\
\hline & $N$ & $\mathrm{n}$ recid & $\mathrm{n}$ recid & $\mathrm{E} / \mathrm{O}$ & $95 \% \mathrm{Cl}$ & $\mathrm{n}$ recid & $\mathrm{E} / \mathrm{O}$ & $95 \% \mathrm{Cl}$ \\
\hline & \multicolumn{8}{|c|}{ Sexual recidivism (5-year) } \\
\hline$<30$ & 311 & 46 & 46.7 & 1.01 & $0.76,1.35$ & 43.3 & 0.94 & $0.70,1.25$ \\
\hline $30 \mathrm{~s}$ & 378 & 58 & 47.4 & 0.82 & $0.63,1.06$ & 42.9 & $0.74^{*}$ & $0.57,0.96$ \\
\hline $40 \mathrm{~s}$ & 348 & 22 & 29.3 & 1.33 & $0.88,2.02$ & 33.1 & 1.50 & $0.99,2.26$ \\
\hline $50 \mathrm{~s}$ & 155 & 13 & 14.7 & 1.13 & $0.66,1.95$ & 16.2 & 1.25 & $0.72,2.15$ \\
\hline \multirow[t]{2}{*}{$\geq 60$} & 76 & 2 & 4.2 & 2.10 & $0.53,8.40$ & 6.5 & 3.25 & $0.81,13.00$ \\
\hline & \multicolumn{8}{|c|}{ Sexual recidivism (10-year) } \\
\hline$<30$ & 255 & 57 & 58.0 & 1.02 & $0.79,1.32$ & 52.5 & 0.92 & $0.60,1.19$ \\
\hline $30 \mathrm{~s}$ & 289 & 68 & 59.7 & 0.88 & $0.69,1.12$ & 53.1 & $0.78^{*}$ & $0.61,0.99$ \\
\hline $40 \mathrm{~s}$ & 232 & 29 & 31.9 & 1.10 & $0.76,1.31$ & 37.4 & 1.29 & $0.90,1.86$ \\
\hline $50 \mathrm{~s}$ & 88 & 9 & 10.8 & 1.20 & $0.62,2.31$ & 12.7 & 1.41 & $0.73,2.71$ \\
\hline$\geq 60$ & 47 & 2 & 2.8 & 1.40 & $0.35,5.60$ & 5.0 & 2.51 & $0.63,10.03$ \\
\hline
\end{tabular}

Note: * significant E/O Index. 5-year $(n=1,268)$ and 10-year $(n=911)$ outcome analyses are reported using all available cases. 5-year logistic regression models: Static-99R and VRS-SO predicted = Static-99R $\left(B_{1}=.194\right)$, VRSSO dynamic pre $\left(B_{1}=.061\right)$, change $\left(B_{1}=-.143\right)$, constant $\left(B_{0}=-4.087\right)$; VRS-SO predicted $=$ VRS-SO total pre $\left(B_{1}=.078\right)$, change $\left(B_{1}=-.150\right)$, constant $\left(B_{0}=-4.483\right)$. 10-year logistic regression models (see also Olver et al., 2018, Table 3, p. 949): Static-99R and VRS-SO predicted $=$ Static-99R $\left(B_{1}=\right.$ $.254)$, VRSSO dynamic pre $\left(B_{1}=.059\right)$, change $\left(B_{1}=-.130\right)$, constant $\left(B_{0}=-3.736\right)$; VRS-SO predicted = VRS-SO total pre $\left(B_{1}=.085\right)$, change $\left(B_{1}=-.148\right)$, constant $\left(B_{0}=-4.124\right)$. 
VRS-SO and Age

Table 12

Calibration: E/O Index Analyses Comparing Observed Rates of 5 and 10-Year Violent Recidivism Among Age Cohorts to Logistic Regression Estimates Generated by VRS-SO Risk and Change Score Combinations (with and without Static-99R).

\begin{tabular}{|c|c|c|c|c|c|c|c|c|}
\hline \multirow[b]{2}{*}{ Age } & \multicolumn{2}{|c|}{ Observed } & \multicolumn{3}{|c|}{ Static-99R and VRS-SO predicted } & \multicolumn{3}{|c|}{ VRS-SO predicted } \\
\hline & $N$ & $\mathrm{n}$ recid & $\mathrm{n}$ recid & $\mathrm{E} / \mathrm{O}$ & $95 \% \mathrm{Cl}$ & $\mathrm{n}$ recid & $\mathrm{E} / \mathrm{O}$ & $95 \% \mathrm{Cl}$ \\
\hline & \multicolumn{8}{|c|}{ Violent recidivism (5-year) } \\
\hline$<30$ & 311 & 104 & 91.6 & 0.88 & $0.73,1.07$ & 82.4 & $0.79 *$ & $0.65,0.96$ \\
\hline $30 \mathrm{~s}$ & 378 & 113 & 95.7 & 0.85 & $0.71,1.02$ & 85.4 & $0.76^{*}$ & $0.63,0.92$ \\
\hline $40 \mathrm{~s}$ & 348 & 47 & 59.6 & 1.27 & $0.95,1.69$ & 68.2 & $1.45^{*}$ & $1.09,1.93$ \\
\hline $50 \mathrm{~s}$ & 155 & 17 & 28.0 & $1.65^{*}$ & $1.03,2.65$ & 32.1 & $1.89 *$ & $1.17,3.04$ \\
\hline$\geq 60$ & 76 & 3 & 7.9 & 2.63 & $0.85,8.15$ & 13.5 & $4.50^{*}$ & $1.45,13.95$ \\
\hline \multicolumn{9}{|c|}{ Violent recidivism (10-year) } \\
\hline$<30$ & 255 & 126 & 112.3 & 0.89 & $0.75,1.06$ & 102.1 & $0.81 *$ & $0.68,0.96$ \\
\hline $30 \mathrm{~s}$ & 289 & 127 & 116.5 & 0.92 & $0.77,1.10$ & 105.3 & $0.83 *$ & $0.70,0.99$ \\
\hline $40 \mathrm{~s}$ & 232 & 61 & 67.7 & 1.11 & $0.86,1.43$ & 77.3 & 1.27 & $0.99,1.63$ \\
\hline $50 \mathrm{~s}$ & 88 & 11 & 22.8 & $2.07 *$ & $1.15,3.74$ & 27.0 & $2.46^{*}$ & $1.36,4.44$ \\
\hline$\geq 60$ & 47 & 2 & 6.4 & 3.20 & $0.80,12.80$ & 11.7 & $5.85^{*}$ & $1.46,23.39$ \\
\hline
\end{tabular}

Note: * significant E/O Index. 5-year $(n=1,268)$ and 10-year $(n=911)$ outcome analyses are reported using all available cases. 5-year logistic regression models: Static-99R and VRS-SO predicted $=$ Static-99R $\left(B_{1}=.243\right)$, VRSSO dynamic pre $\left(B_{1}=.052\right)$, change $\left(B_{1}=-.138\right)$, constant $\left(B_{0}=-3.157\right) ;$ VRS-SO predicted $=$ VRS-SO total pre $\left(B_{1}=.074\right)$, change $\left(B_{1}=-.147\right)$, constant $\left(B_{0}=-3.424\right)$. 10-year logistic regression models (see also Olver et al., 2018, Table 4, p. 950): Static-99R and VRS-SO predicted = Static-99R $\left(B_{1}=\right.$ $.282)$, VRSSO dynamic pre $\left(B_{1}=.049\right)$, change $\left(B_{1}=-.123\right)$, constant $\left(B_{0}=-2.509\right)$; VRS-SO predicted = VRS-SO total pre $\left(B_{1}=.078\right)$, change $\left(B_{1}=-.147\right)$, constant $\left(B_{0}=-2.788\right)$. 


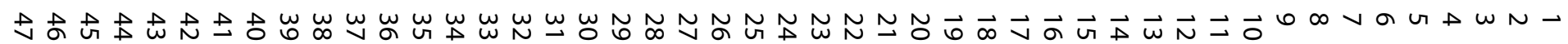

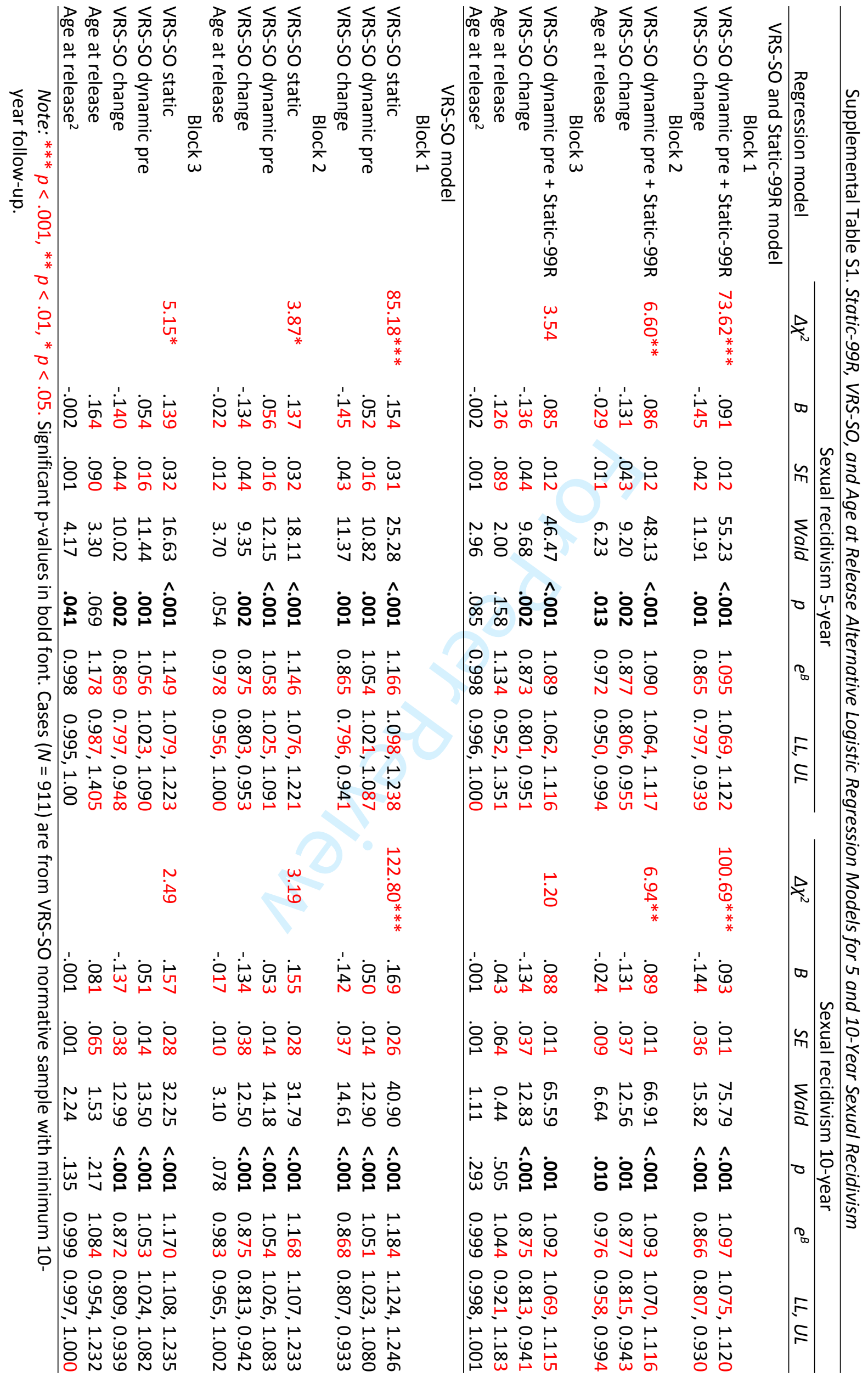

